Ecological Modelling

2

3

4

5

6

7

8

\title{
Multi-site Calibration and Validation of a Net Ecosystem Carbon Exchange Model for Croplands
}

\author{
A. Klosterhalfen ${ }^{\mathrm{a}}$, M. Herbst ${ }^{\mathrm{a}}$, L. Weihermüller ${ }^{\mathrm{a}}$, A. Graf $^{\mathrm{a}}$, M. Schmidt ${ }^{\mathrm{a}}$, A. Stadler ${ }^{\mathrm{b}}$, \\ K. Schneider ${ }^{c}$, J.-A. Subke ${ }^{\text {d }}$ J.A. Huisman ${ }^{\mathrm{a}}$, H. Vereecken ${ }^{\mathrm{a}}$
}

Anne Klosterhalfen, a.klosterhalfen@fz-juelich.de, corresponding author

Michael Herbst, m.herbst@fz-juelich.de

Lutz Weihermüller,1.weihermueller@fz-juelich.de

Alexander Graf, a.graf@fz-juelich.de

Marius Schmidt, ma.schmidt@fz-juelich.de

Anja Stadler, astadler@uni-bonn.de

Karl Schneider, karl.schneider@uni-koeln.de

Jens-Arne Subke, jens-arne.subke@stir.ac.uk

Johan Alexander Huisman, s.huisman@fz-juelich.de

Harry Vereecken, h.vereecken@fz-juelich.de

a Agrosphere Institute, IBG-3, Forschungszentrum Jülich GmbH, 52425 Jülich, Germany

${ }^{\mathrm{b}}$ Institute of Crop Science and Resource Conservation, University of Bonn, 53115 Bonn, Germany

${ }^{\mathrm{c}}$ Institute of Geography, University of Cologne, 50923 Cologne, Germany

${ }^{\mathrm{d}}$ School of Natural Sciences, University of Stirling, Stirling, FK9 4LA, UK 


\section{ABSTRACT}

2 Croplands play an important role in the carbon budget of many regions. However, the

3 estimation of their carbon balance remains difficult due to diversity and complexity of the

4 processes involved. We report the coupling of a one-dimensional soil water, heat, and $\mathrm{CO}_{2}$

5 flux model (SOILCO2), a pool concept of soil carbon turnover (RothC), and a crop growth

6 module (SUCROS) to predict the net ecosystem exchange (NEE) of carbon. The coupled

7 model, further referred to as AgroC, was extended with routines for managed grassland as

8 well as for root exudation and root decay. In a first step, the coupled model was applied to

9 two winter wheat sites and one upland grassland site in Germany. The model was calibrated

based on soil water content, soil temperature, biometric, and soil respiration measurements for each site, and validated in terms of hourly NEE measured with the eddy covariance technique. The overall model performance of AgroC was sufficient with a model efficiency above 0.78 and a correlation coefficient above 0.91 for NEE. In a second step, AgroC was optimized with eddy covariance NEE measurements to examine the effect of different objective functions, constraints, and data-transformations on estimated NEE. It was found that NEE showed a distinct sensitivity to the choice of objective function and the inclusion of soil respiration data in the optimization process. In particular, both positive and negative day- and nighttime fluxes were found to be sensitive to the selected optimization strategy. Additional consideration of soil respiration measurements improved the simulation of small positive fluxes remarkably. Even though the model performance of the selected optimization strategies did not diverge substantially, the resulting cumulative NEE over simulation time period differed substantially. Therefore, it is concluded that data-transformations, definitions of objective functions, and data sources have to be considered cautiously when a terrestrial ecosystem model is used to determine NEE by means of eddy covariance measurements.

Keywords: AgroC, soil respiration, carbon balance, winter wheat, grassland, NEE 


\section{1. Introduction}

2 Terrestrial ecosystems play an important role in the global carbon cycle. Photosynthesis by

3 vegetation and respiration from autotrophic and heterotrophic organisms represent the two

4 major carbon fluxes between atmosphere and terrestrial biosphere. Terrestrial ecosystems

5 store large amounts of carbon, and especially soils contain about twice as much carbon as the

6 atmosphere (Rustad et al., 2000). Over 37\% of the world's landmass is agricultural land (FAO

7 Statistical Yearbook, 2014). Thus, carbon fluxes in agroecosystems constitute a significant

8 part of the global carbon cycle. The quantification and prediction of terrestrial carbon sinks

9 and sources and their dynamics, variabilities, and controls are of major importance for climate

10 change research and the optimization of management strategies affecting the ecosystem's

11 carbon budget (e.g., Baldocchi, 2003; Kuzyakov, 2006; Subke et al., 2006). The net

12 ecosystem exchange (NEE) of carbon dioxide and its two components, gross primary production (GPP) and terrestrial ecosystem respiration (TER), are of particular interest

14 (Suleau et al., 2011; Sus et al., 2010). The total $\mathrm{CO}_{2}$ efflux from soils, one of the major compartments of TER (Moureaux et al., 2008; Suleau et al., 2011), derives from decomposition of soil organic matter and dead plant material by microorganisms, from direct root respiration, and from microbial respiration of root exudates and rhizodepositions (Kuzyakov, 2006; Kuzyakov and Domanski, 2000). In this study, we consider the last two $\mathrm{CO}_{2}$ sources as one sum, and refer to it as "rhizosphere respiration".

NEE is increasingly being monitored using the eddy covariance (EC) technique, which provides information on net carbon fluxes for a relatively large area with a high temporal resolution (Baldocchi, 2003). This allows to investigate the relation between $\mathrm{CO}_{2}$ efflux and weather conditions or crop development stages (Sus et al., 2010). Due to methodological and technical constraints, significant gaps occur in high-quality EC data, which prohibits direct computation of annual NEE. Gap-filling methods (e.g., Reichstein et al., 2005) and their 
1 application with meteorological and EC data overcome this limitation, but e.g., they cannot be 2 used for predictive modeling of carbon balances addressing climate change effects. 3 Alternatively, terrestrial ecosystem models that provide a physical description of processes in

4 the agroecosystem can be used to assess annual NEE sums. An additional advantage of such 5 models is that they allow to quantify interrelations and feedbacks in biogeochemical processes 6 and fluxes of agricultural systems. Mechanistic models like ORCHIDEE-STICS (de 7 Noblet-Ducoudré et al., 2004), DNDC (Li et al., 2005), or SPAc (Sus et al., 2010) were developed for this purpose and have been successfully applied in a number of studies (e.g.,

9 Sus et al., 2010; Wattenbach et al., 2010; Wu et al., 2009; Yuan et al., 2012). In most of these studies, the carbon assimilation by plants was captured well by the models, but a significant bias in the simulation of the respiratory fluxes was observed. This inevitably causes systematic errors in the estimation of the overall carbon balance. An improved representation of processes linked to respiration may help to decrease systematic errors and in combination with soil respiration $\left(\mathrm{R}_{\text {soil }}\right)$ measurements, it may help to reduce the uncertainty in the estimation of annual NEE. For this purpose, we coupled a one-dimensional soil water, heat, and $\mathrm{CO}_{2}$ flux model (SOILCO2; Šimůnek and Suarez, 1993), a pool concept of soil carbon turnover (RothC; Coleman and Jenkinson, 2008), and a crop growth module (SUCROS; Spitters et al., 1989). In addition, the coupled model, further referred to as AgroC, was extended with routines for root exudation, root decay, as well as for a managed grassland system. The main motivation for the coupling was a more detailed representation of sources and locations of $\mathrm{CO}_{2}$ production, the gas transport in the soil, and the fluxes in the ecosystem. Various sources of measured data are available for validation, calibration, evaluation, and structural improvement of terrestrial ecosystem models. In the last decade, substantial progress has been made in implementing model-data fusion techniques to make optimal use of available measurements (e.g., Richardson et al., 2010; Sus et al., 2010; Trudinger et al., 
1 2007; Wu et al., 2009; Yuan et al., 2012). Such model-data fusion techniques, including

2 calibration techniques, require the formulation and minimization of an objective function that 3 quantifies the mismatch between model predictions and observations (Evans, 2003; Herbst et

4 al., 2008; Wang et al., 2009). Detailed measurements of biotic and abiotic processes and 5 fluxes allow to improve process models on various spatiotemporal scales, and to verify model 6 assumptions, parameters, and performance (Richardson et al., 2010; Williams et al., 2009; 7 Yuan et al., 2012). However, the use of multiple objective functions or constraints in model 8 calibration may be challenging because of the need to combine measurements with variable 9 spatial scale, temporal scale, magnitude, and uncertainty. For example, optimizing the simulation regarding one data source (e.g., NEE) can lead to a low model performance (tradeoff) regarding another data source (e.g., heterotrophic soil respiration) (Richardson et al., 2010). Other important decisions to be made before model calibration include the selection and appropriate weighting of observations, the choice of an optimization algorithm (Trudinger et al., 2007), and the selection of model parameters being altered during calibration (Wu et al., 2009). These decisions differ between model studies, which will influence the results of NEE predictions (Evans, 2003; Trudinger et al., 2007).

17 The main goal of this study is to present the mechanistic model AgroC and to evaluate its model performance simulating biophysical processes and interactions in agroecosystems. In a first step, AgroC was calibrated with soil moisture, soil temperature, biometric, and soil $\mathrm{CO}_{2}$ flux measurements of three test sites in Germany cropped with winter wheat, barley, or grass. 21 After calibration, it was evaluated how well AgroC simulates the hourly NEE through 22 comparison with EC measurements. In the next step, we optimized the AgroC model using EC measurements by estimating plant and $\mathrm{R}_{\text {soil }}$ parameters. In addition, we evaluated how joint use of $\mathrm{EC}$ and $\mathrm{R}_{\text {soil }}$ measurements in the calibration affected the estimated cumulative 
1 NEE and model performance. Finally, we evaluated the effect of data-transformation (e.g.,

2 log-transformation) on the model results with a focus on estimated NEE.

\section{Materials and Methods}

\subsection{The AgroC Model}

AgroC is a coupled model developed from the SOILCO2/RothC model (Herbst et al., 2008) and the SUCROS model for crop growth (Spitters et al., 1989). The SOILCO2/RothC model simulates vertical water, heat, and $\mathrm{CO}_{2}$ fluxes in a soil column, and the source term of heterotrophic respiration over soil depth and time, which is given by the turnover of depthspecific carbon pools (Coleman and Jenkinson, 2008; Šimůnek and Suarez, 1993; Šimůnek et al., 1996). The carbon turnover rates depend on the soil water content and temperature. The SOILCO2/RothC model was validated in several laboratory and field studies (Bauer et al., 2008, 2012; Herbst et al., 2008; Palosuo et al., 2012; Weihermüller et al., 2009). The coupling with SUCROS is expected to allow for an improved simulation of the soil autotrophic respiration source term, since temporal development of root growth and related growth and maintenance respiration is simulated by SUCROS in a mechanistic way. In addition, AgroC was extended with routines for the simulation of root exudation, root decay, and managed grassland. The latter routine follows the sink/source approach suggested by Schapendonk et al. (1998) for the grassland productivity model LINGRA. The final coupled model allows closing the one-dimensional carbon balance and to estimate NEE, since carbon assimilation as well as organ-specific growth and maintenance respiration are now included. Figure 1 provides a summary of the carbon cycling in AgroC.

The coupled SOILCO2/RothC model allows the use of user-specified length and time units, whereas the SUCROS module uses fixed units. For the coupled AgroC model, we preserved the flexibility in terms of length ([L]) and time units ([T]), but we kept the fixed mass and 
1 area units (kg, ha) of the original SUCROS code. Also, the final coupled AgroC model works

2 with an hourly time step. Further information about the coupling and the modifications to the 3 original models regarding the hourly time step, the water fluxes, the carbon fluxes, and the 4 grassland routines are given in the Appendix A. 


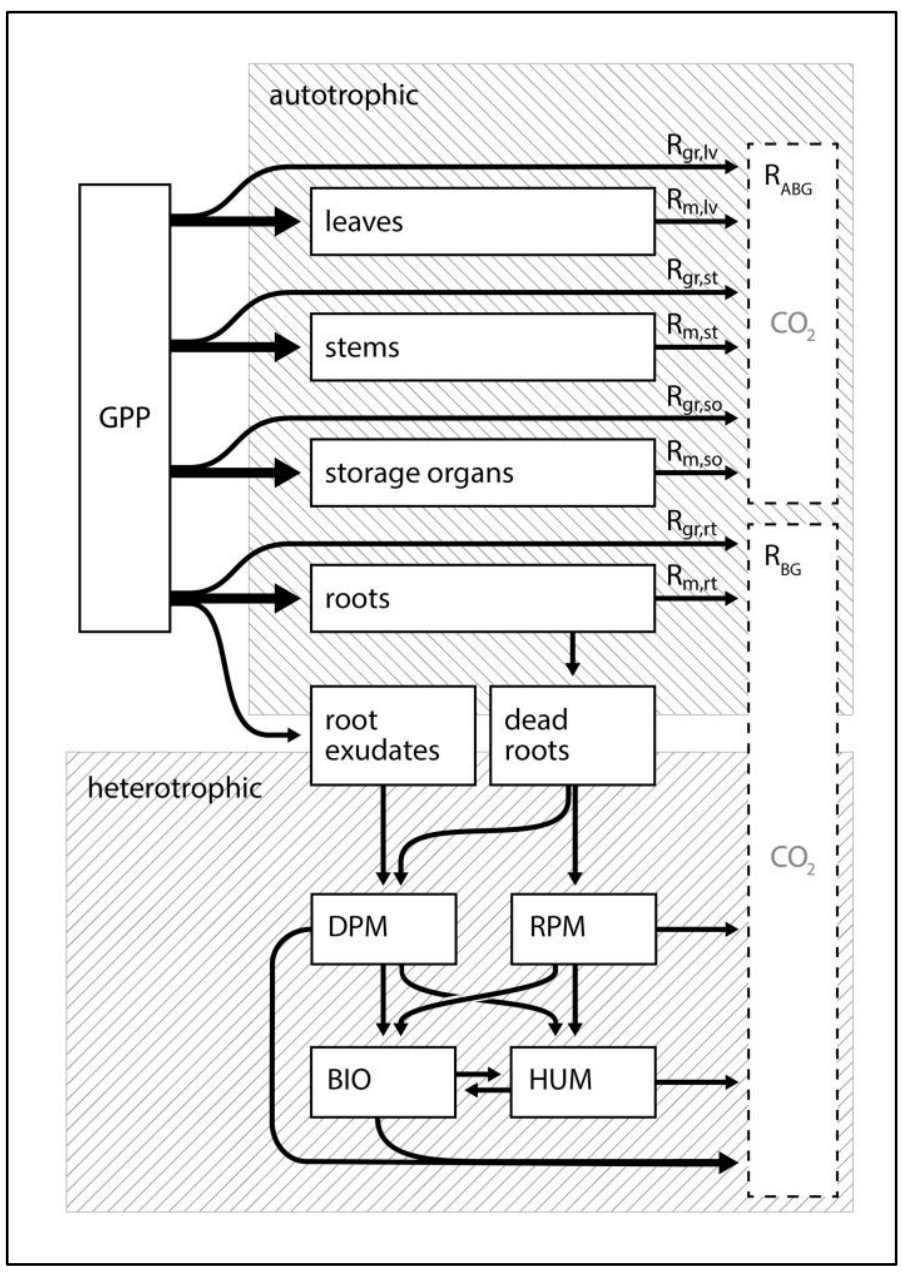

2

3 Fig. 1:

4 Carbon fluxes and partitioning in AgroC. Gross primary production (GPP) is partitioned to 5 the different plant organs, leaves (subscript lv), stems (st), storage organs (so), and roots (rt). $6 \mathrm{CO}_{2}$ is lost due to growth $\left(\mathrm{R}_{\mathrm{gr}}\right)$ and maintenance respiration $\left(\mathrm{R}_{\mathrm{m}}\right)$. The sum of these 7 autotrophic $\mathrm{CO}_{2}$ source terms by the shoot organs account for the above-ground respiration $8 \quad\left(\mathrm{R}_{\mathrm{ABG}}\right)$. Carbon and $\mathrm{CO}_{2}$ is added to the soil profile by autotrophic root respiration, root exudates, and dead roots. The latter two are transferred to the decomposable and resistant

10 plant material pool (DPM, RPM) of the RothC model and decomposed. The heterotrophic $11 \mathrm{CO}_{2}$ source term consists of microbial decomposition of those and further soil organic matter 12 pools (humified organic matter HUM, microbial biomass BIO). The root respiration and the 13 heterotrophic components are part of the below-ground respiration $\left(\mathrm{R}_{\mathrm{BG}}\right)$. 


\subsection{Study Sites and Data Availability}

AgroC was applied to three experimental sites in the western part of Germany: Selhausen and Merzenhausen, both located in the southern part of the Lower Rhine Embayment (Schmidt et al., 2012; Stadler et al., 2015), and Rollesbroich, located in the low mountain range Eifel (Gebler et al., 2015). The dominant land use at the first two test sites is cropland. Rollesbroich is a managed grassland site, which is mown three times per year (Borchard et al., 2015). All three study sites are included in the Terrestrial Environmental Observatories (TERENO) network of highly instrumented field sites (Zacharias et al., 2011). An overview of soil properties, meteorological conditions, and crop management is given in Tables 1 and A.1 for all three sites.

At the two cropland sites, EC and ancillary environmental measurements were conducted in the center of the agricultural fields. Measurements of NEE, latent heat, wind components, global radiation, air temperature, soil (surface) temperature at a depth of $-1 \mathrm{~cm}$, precipitation, and relative humidity were collected. A detailed description of the sites, measurement setup, EC post-processing, and footprint modelling is given by Schmidt et al. (2012), Graf et al. (2013), Post et al. (2015), Mauder et al. (2013) and Kormann and Meixner (2001). Soil water content and soil temperature were measured in various depths at several soil profiles per site. Biometric measurements were carried out bi-weekly to monitor crop development, and $\mathrm{R}_{\text {soil }}$ data were obtained with closed-chamber measurements during summer (Prolingheuer et al., 2014; Schmidt et al., 2012; Stadler et al., 2015). Prolingheuer et al. (2014) also measured the heterotrophic contribution to the $\mathrm{CO}_{2}$ flux by root exclusion experiments at 61 sample points at the Selhausen test site.

In Rollesbroich, the EC tower was placed between two neighboring grasslands (A and B) with different management in terms of mowing dates. Thus, measured fluxes were dominated by one of the two grasslands depending on the wind direction and the resulting flux footprint 
1 distribution. Data processing was similar to the two agricultural fields. Borchard et al. (2015)

2 conducted detailed surveys of the Rollesbroich site. At 21 sample points in grassland A, soil

3 samples were taken, and the total leaf area index (LAI) and harvested dry matter were also

4 determined during the growing season. Eleven of the sampling points were mown following

5 the management of grassland $\mathrm{A}$, and the remaining 10 points were sampled following the

6 management of grassland B. $\mathrm{R}_{\text {soil }}$ was again determined from closed-chamber measurements

7 during summer. Soil moisture, soil temperature, and $\mathrm{CO}_{2}$ concentration in several depths were

8 observed at three profiles near the EC tower. 
1 Tab. 1:

2 Site-specific characteristics, meteorological conditions, and crop management (WW: Winter

3 wheat; WB: winter barley; GL: grassland) (Borchard et al., 2015; Gebler et al., 2015;

4 Prolingheuer et al., 2014; Schmidt et al., 2012; Séquaris et al., 2013; Stadler et al., 2015).

5

\begin{tabular}{|c|c|c|c|}
\hline & Selhausen & Merzenhausen & Rollesbroich \\
\hline $\begin{array}{l}\text { Site characteristics } \\
\text { coordinates }\end{array}$ & $\begin{array}{l}50^{\circ} 52^{\prime} 14^{\prime \prime} \mathrm{N} \\
6^{\circ} 26^{\prime} 59^{\prime \prime} \mathrm{E}\end{array}$ & $\begin{array}{l}50^{\circ} 55^{\prime} 47^{\prime} ' \mathrm{~N} \\
6^{\circ} 17^{\prime} 49^{\prime \prime} \mathrm{E}\end{array}$ & $\begin{array}{l}50^{\circ} 37^{\prime} 19^{\prime \prime} \mathrm{N}, \\
6^{\circ} 18^{\prime} 15^{\prime \prime} \mathrm{E}\end{array}$ \\
\hline $\begin{array}{l}\text { elevation (m a.s.l.) } \\
\text { soil type } \\
\text { soil texture }\end{array}$ & $\begin{array}{l}103 \\
\text { Luvisol } \\
\text { silt loam }\end{array}$ & $\begin{array}{l}93 \\
\text { Luvisol } \\
\text { silt loam }\end{array}$ & $\begin{array}{l}515 \\
\text { Cambisol } \\
\text { silty clay }\end{array}$ \\
\hline $\begin{array}{l}\text { Climate conditions } \\
\text { mean annual temperature }\left({ }^{\circ} \mathrm{C}\right) \\
\text { annual precipitation }(\mathrm{mm})\end{array}$ & $\begin{array}{l}9.9 \\
698\end{array}$ & $\begin{array}{l}9.9 \\
698\end{array}$ & $\begin{array}{l}7.7 \\
1033\end{array}$ \\
\hline Simulation period & Oct 2008 - Dec 2009 & Oct 2011 - Dec 2014 & Jan 2013 - Dec 2013 \\
\hline $\begin{array}{l}\text { Land management } \\
\text { crop sequence }\end{array}$ & $\begin{array}{l}\text { WW } \\
\text { tilled every autumn }\end{array}$ & $\begin{array}{l}\text { WW - WW - WB } \\
\text { tilled every autumn }\end{array}$ & $\begin{array}{l}\text { GL } \\
\text { mowed } 3 x \text { annually }\end{array}$ \\
\hline
\end{tabular}




\subsection{Model Setup and Initialization}

AgroC requires gap-filled meteorological data (air temperature, soil surface temperature, precipitation, solar radiation, and potential grass reference evapotranspiration), plant-specific parameters, and soil characteristics. Potential grass reference evapotranspiration was estimated with the Penman-Monteith approach according to the FAO guidelines (Allen et al., 1998). Plant-specific parameters for cereals and grass were mainly taken from literature (e.g., Boons-Prins et al., 1993; Gonzales et al., 1989; Goudriaan et al., 1997; Kuzyakov and Domanski, 2000; Parsons, 1988; Parsons and Robson, 1981; Prud'homme et al., 1992;

Schapendonk et al., 1998; Spitters et al., 1989; Swinnen et al., 1995; Vanclooster et al., 1995; van Keulen et al., 1997). These plant parameters have been extensively used in other simulation studies with the models SUCROS and LINGRA. Root biomass measurements were not available, thus the proportion of the root system (root/shoot ratio) was also derived from literature (e.g., Bolinder et al., 1997, 2002; López et al., 2013).

In AgroC, appropriate boundary conditions have to be specified for $\mathrm{CO}_{2}$, water, and heat flow at the top and bottom of the simulation domain. The upper boundary condition for $\mathrm{CO}_{2}$ flow was the atmospheric concentration of $0.038 \%$. Meteorological measurements were used to describe the upper boundary for water and heat flux. Soil profile characteristics were available from Séquaris et al. (2013), Herbst et al. (2005), and Borchard et al. (2015) for Selhausen, Merzenhausen, and Rollesbroich, respectively (Tab. A.1). The simulated profile depths varied from 1.0 to $1.2 \mathrm{~m}$. A no-flow boundary was used at the bottom of the soil profile for heat and $\mathrm{CO}_{2}$. For water, a prescribed pressure head following a sine wave over the course of the year with a minimum in autumn was used as a Dirichlet boundary condition at the bottom of the simulation domain (Bauer et al., 2008; Scharnagl et al., 2011).

Initial carbon pool sizes were derived from measured soil organic carbon contents for each soil horizon. In Selhausen and Rollesbroich, measured soil carbon fractions were available 
1 from previous studies (Bauer et al., 2012; Séquaris et al., 2013; Nils Borchard and Henning

2 Schiedung, personal communication). For these two sites, initial pool sizes were calculated

3 following Falloon et al. (1998), Skjemstad et al. (2004), and Zimmermann et al. (2007). For

4 Merzenhausen, initial pool sizes were determined with pedotransfer functions according to

5 Weihermüller et al. (2013), assuming a state of equilibrium. The reference temperature

6 required for the estimation of the soil heterotrophic $\mathrm{CO}_{2}$ source term was set to the mean

7 annual temperature at each site.

\subsection{Model Calibration}

In a first step, AgroC was calibrated with the downhill Nelder-Mead Simplex algorithm (Nelder and Mead, 1965), since only a small number of parameters were considered. The root mean square error (RMSE) between measurements and simulations was minimized. In addition, the Pearson product-moment correlation coefficient $(r)$ and the model efficiency $(M E)$ (Nash and Sutcliffe, 1970) were calculated as model quality criteria. A $M E$ close to 1 indicates that the simulation describes the observations well without systematic bias. If $M E$ is lower than 0 , the mean of the observations is a better predictor than the simulation.

First, the soil hydraulic parameters were calibrated. Then, plant development and growth were adjusted. Here, mainly the plant development rate depending on temperature, the effectiveness of $\mathrm{CO}_{2}$ assimilation, the partitioning factors of assimilates between the different plant organs, especially between shoot and root system, and the specific leaf area (conversion

21 factor between plant dry matter and LAI) were modified (Tab. A.2).

$22 \mathrm{CO}_{2}$ production in the soil profile was estimated in dependence of several physical processes and conditions. For soil temperature, we used the default reduction function of the SOILCO2 model, which is a modified form of the Arrhenius relationship (Šimůnek and Suarez, 1993; Šimůnek et al., 1996). To describe the soil moisture dependency of respiration, we applied a 
1 bell-shaped curve as suggested by Bauer et al. (2012), Moyano et al. (2012), and Skopp et al.

2 (1990). The simulation of $R_{\text {soil }}$ was improved by calibrating the reference temperature used in

3 the temperature scaling function, the turnover rate of the resistant plant material (RPM) pool,

4 and the parameters of the water reduction function. For Rollesbroich, soil $\mathrm{CO}_{2}$ concentration

5 measurements in different depths were available, so the gaseous diffusion through the soil

6 matrix could also be adjusted. Here, we implemented the gas diffusivity and transport model

7 of Kristensen et al. (2010), which accounts for preferential diffusion through fractures and macropores in the soil matrix. Appendant parameters, the fracture porosity, the fracture tortuosity factor, and the matrix tortuosity factor, were adjusted.

After soil water, soil heat, and $\mathrm{CO}_{2}$ flux, as well as plant development were calibrated, we compared the NEE estimates with the EC measurements at each test site. NEE measurements were handled according to the quality assessment strategy suggested by Mauder et al. (2013), and only data with high quality was used for validation purposes (28\% of data in Selhausen; $55 \%$ of data in Merzenhausen; $33 \%$ of data in Rollesbroich).

In a second step, several model runs were conducted where simulated NEE was optimized with EC measurements by estimating plant parameters (regarding the light use efficiency, the potential $\mathrm{CO}_{2}$ assimilation rate, their dependence on crop development stage and air temperature, and the biomass partitioning factors between shoot and root), and model parameters affecting $\mathrm{R}_{\text {soil }}$ (as above: reference temperature, turnover rate of RPM, and parameters of the water reduction function). Here, parameter calibration was conducted with

21 the Shuffled Complex Evolution (SCE) algorithm (Duan et al., 1993), which is a global optimization strategy that was shown to be effective for a wide range of non-linear optimization problems. Two different objective functions were considered: (i) the RMSE and (ii) the sum of the RMSE and the Bias. The former was calculated on the basis of various data expressions (instantaneous data, cumulative data, or instantaneous log-transformed data). 
1 Additional calibrations were conducted that not only considered NEE data for the

2 optimization, but also measurements of $\mathrm{R}_{\text {soil }}$. Therefore, we considered a total of eight 3 different calibration strategies (see Tab. 2). Because of the different magnitude of NEE and

$4 \quad \mathrm{R}_{\text {soil }}$ (and resulting misfits), the error was transformed by division with the respective 5 observed mean flux (with the exception of $N E E_{B S c}$ approach). For each test site, these eight 6 calibrations were conducted to examine the sensitivity of estimated cumulative NEE to the 7 different objective functions and to the inclusion of $\mathrm{R}_{\text {soil }}$ measurements. Estimated cumulative 8 NEE based on each optimization strategy was compared to the well-established gap-filling 9 method by Reichstein et al. (2005), which is based on linear regressions between EC 10 measurements and physical drivers. 
1 Tab. 2:

2 Applied optimization strategies and their objective functions, used data streams and data

3 transformation ( $o b s \_N$ : NEE observation; $s i m \_N$ : NEE simulation; $o b s \_R$ : $\mathrm{R}_{\text {soil }}$ observation;

4 sim_R: $\mathrm{R}_{\text {soil }}$ simulation).

5

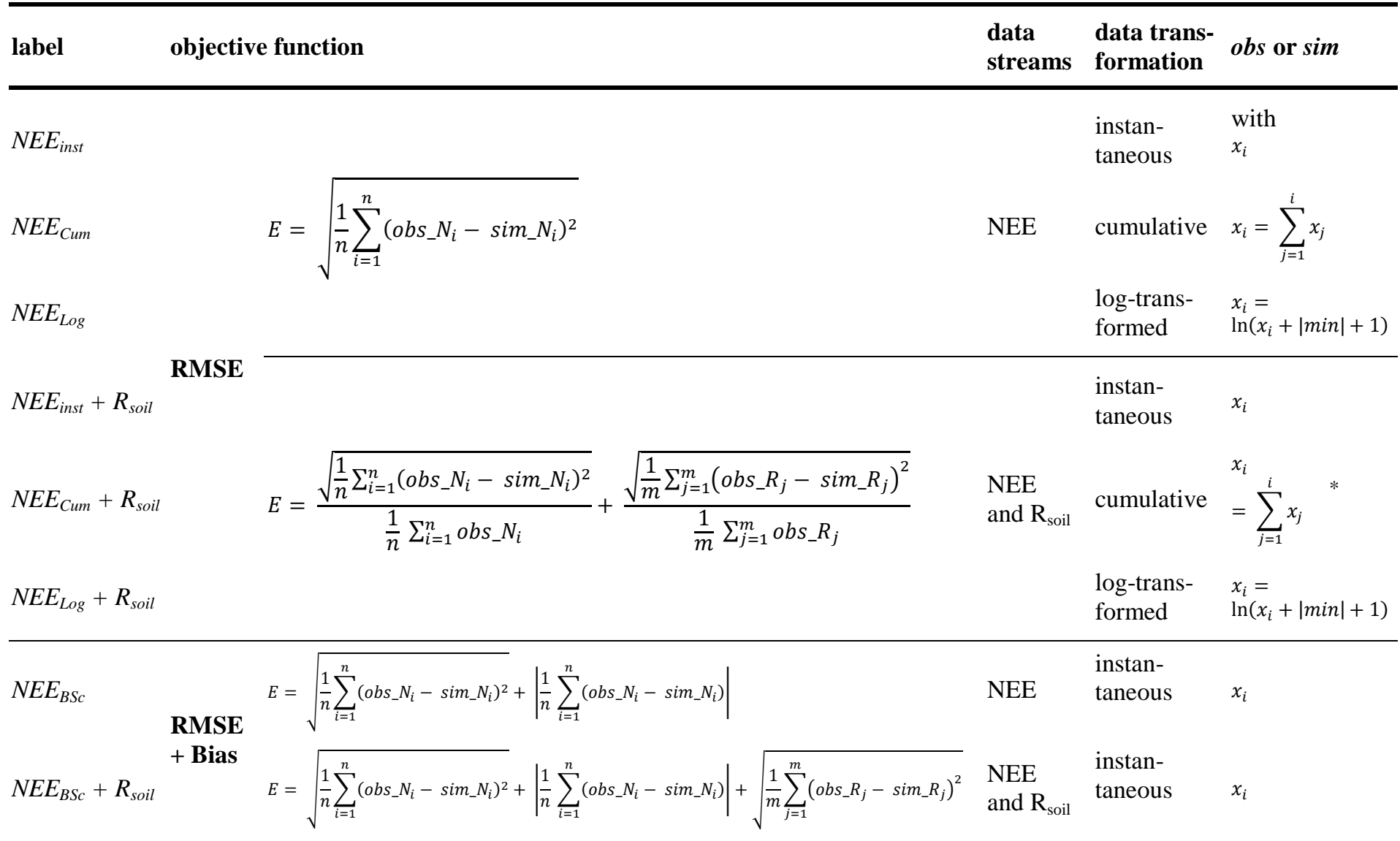

* only applied to NEE data, $\mathrm{R}_{\text {soil }}$ data was used instantaneous. 


\section{3. Results and Discussion}

2 3.1. Calibration and Validation of AgroC

3 Soil Temperature and Water Content

4 All simulations described measured soil temperature very well using the default settings. The

$5 \quad R M S E$ was below $1.0^{\circ} \mathrm{C}$ and the $M E$ larger than 0.93 when measurements for all depths and

6 sites were considered (see Fig. 2).

7 After calibration, the soil moisture dynamics were reproduced well by the AgroC model 8 (Fig. 3). Estimated soil hydraulic parameters are summarized in Table A.1. The RMSE was 9 below $0.020 \mathrm{~cm} \mathrm{~cm}^{-3}$, the $M E$ above 0.74 and the $r$ above 0.86 for all sites and profile depths. 10 For Merzenhausen, the model was calibrated for 2012 and the following two years were used 11 for validation. The performance of the model decreased for the validation period, but overall 12 dynamics were still reproduced well (Fig. 3). Some near-surface peaks in soil moisture were not captured by the model, which is probably related to inaccuracies in the meteorological

14 data used for the upper boundary condition. Furthermore, static hydraulic properties were 15 assumed for the AgroC simulations, which is a simplification because hydraulic properties of 16 managed topsoils are typically variable due to ploughing, seedbed preparation, and 17 subsequent re-compaction. For the Rollesbroich site, soil moisture simulations at $-5 \mathrm{~cm}$ differed from the observations during winter. This is partly related to the presence of a snow cover, which results in delayed infiltration not represented in the model, and frozen soil,

20 which affects soil water content measurements with the dielectric sensors used in this study. 

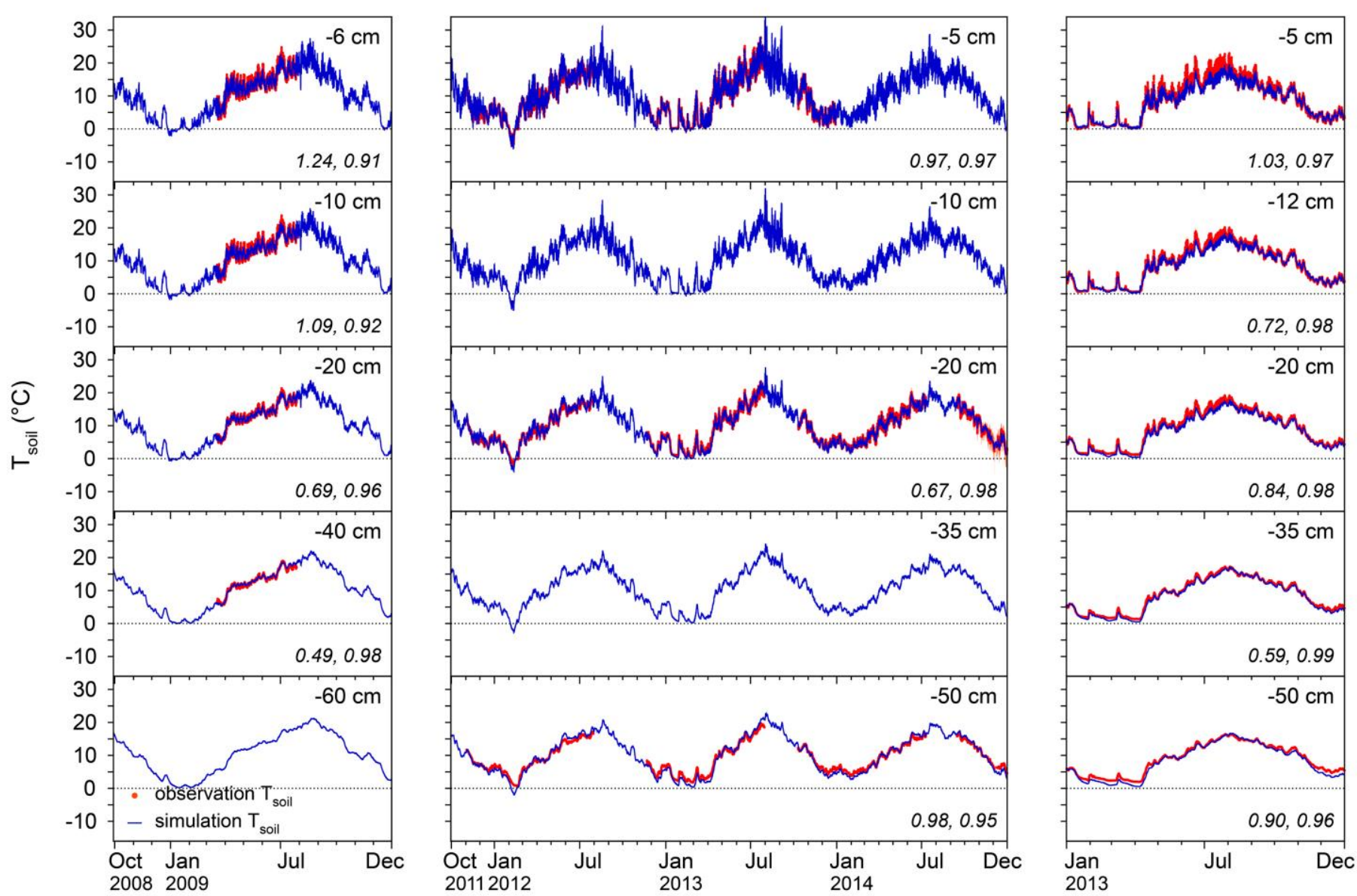

2 Fig. 2:

3 Observed (dots; orange area: standard deviation) and simulated (lines) soil temperature $\left(\mathrm{T}_{\text {soil }}\right)$

4 in several depths in Selhausen (left), Merzenhausen (middle), and Rollesbroich (right). Root

5 mean square error (RMSE) and model efficiency (ME) (in this order) are given for each soil

6 depth and location. 

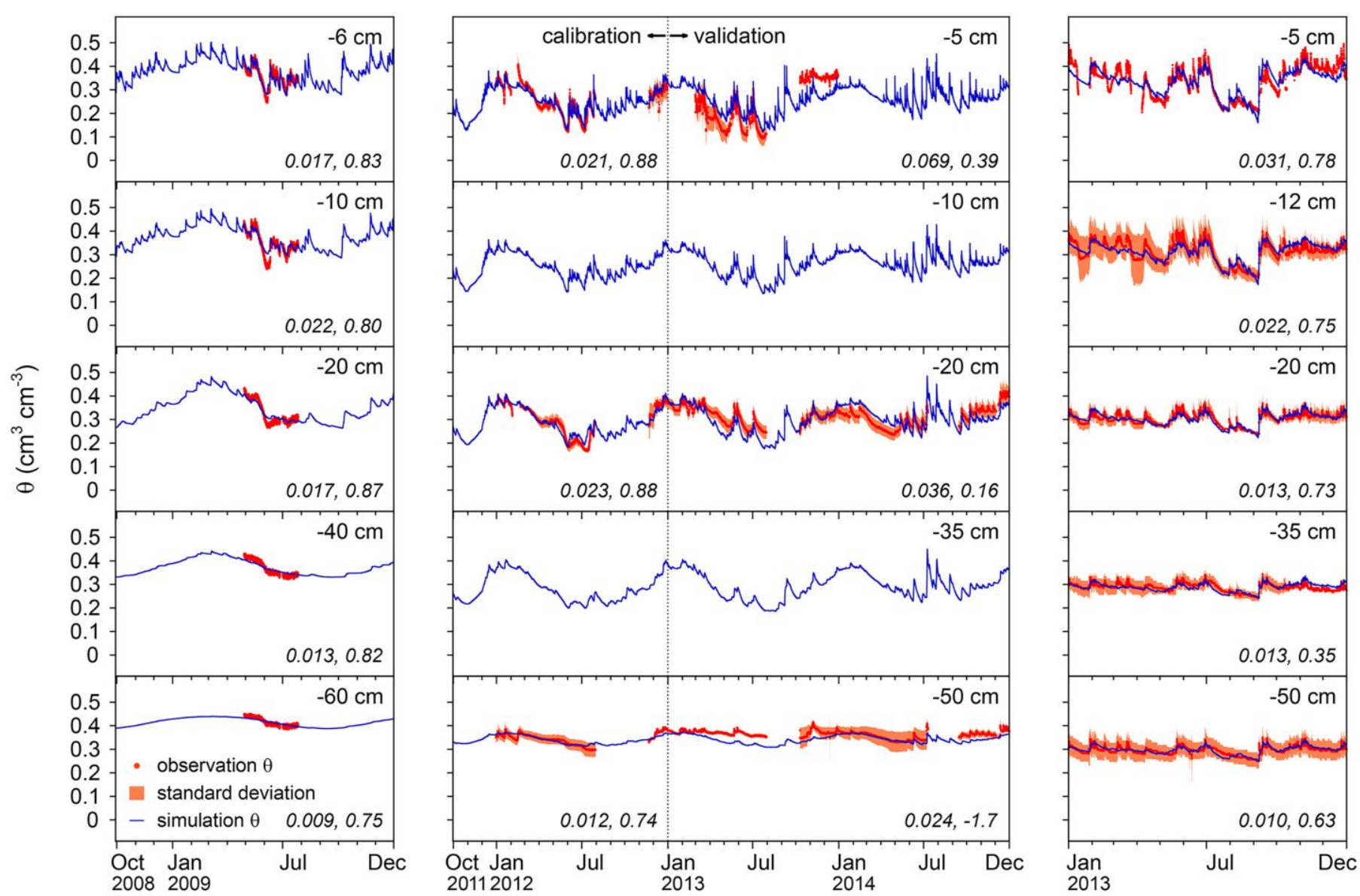

2 Fig. 3:

3 Observed (dots; orange area: standard deviation) and simulated (lines) soil water content $(\theta)$

4 at various depths in Selhausen (left), Merzenhausen (middle), and Rollesbroich (right). Root 5 mean square error (RMSE) and model efficiency (ME) (in this order) are given for each soil

6 depth and location. In Merzenhausen, RMSE and ME are given for the calibration (until end 7 of 2012) and the validation period. 


\section{Crop Development and Growth}

Without calibration, simulated crop development and dry matter accumulation over time were already close to the observations (not shown). For further improvement, plant-specific parameters were manually adjusted (Fig. 4, 5). In general, the assimilation rate, the fraction of the root biomass, and the specific leaf area were increased for all crops at all test sites. In Table A.2 in the appendix, the most relevant plant parameters are summarized. For total LAI, the lowest $M E$ was $0.63, R M S E$ was lower than 0.82 ha ha $^{-1}$, and $r$ was larger than 0.93 for all sites. Site-specific errors for green and brown LAI are provided in Figure 4. As can be seen, green LAI was well reproduced over the growing season, while the course of brown LAI was simulated less well. As indicated by the $M E$ in Figure 5, the simulation of dry matter was adequate too, especially for winter wheat in Selhausen. However, the simulations progressively diverged from the measurements towards crop maturity. For cereals, this might be due to the fact that reallocation of assimilates from leaves and stem to storage organs was not implemented in AgroC (Spitters et al., 1989).

In Merzenhausen, LAI and biomass measurements were only conducted at harvest in 2012 and during the entire growing season in 2013 (both winter wheat). For model calibration over the complete simulation period, measurements of plant height were therefore considered. A relation between LAI and plant height was determined for 2013. Plant height showed distinct differences between 2012 and 2013. In 2013, a smaller height and consequently a lower LAI and dry matter allocation were observed. This could not be reproduced by the model when only differences in meteorological conditions between the two years were considered. Winter wheat varieties and management differed between the two cultivation periods, and according to Spitters et al. (1989), plant parameters can vary substantially between species. In addition, it needs to be considered that the spring of 2013 was much drier than usual. Even though water stress was explicitly accounted for in AgroC, irreversible damages (e.g., by heat stress) 
1 of plant tissue might have caused a reduced growth beyond the water stress period.

2 Furthermore, the root system may have preferably been expanded relative to the shoots due to

3 the water deficit. These effects were not directly considered in AgroC, and could only be

4 captured by different parameterizations. Therefore, we ran AgroC with crop parameter sets

5 for winter wheat that differed between the two cultivation periods.

6 The Rollesbroich grassland site was covered by snow until the beginning of April 2013, thus

7 plant growth was delayed. The model was fitted to the plant development and growth on

8 parcel A. For the simulation of parcel B, only the dates of mowing were adjusted. This

9 resulted in an adequate simulation for LAI and dry matter allocation of both grassland parcels

10 (Fig. 4, 5).

11 At the day of harvest, the simulations for Selhausen and Merzenhausen resulted in mean

12 root/shoot dry matter ratios of 0.08 and 0.16, respectively. Bolinder et al. (1997, 2002)

13 determined root/shoot ratios between 0.13 and 0.20 for winter wheat. Compared to this, the

14 simulated root/shoot ratio for Selhausen was rather low. However, observations of

15 rhizospheric respiration at this test site (Fig. 6) confirmed the estimated partitioning of

16 assimilates between shoot and roots. For the Rollesbroich grassland site, the mean root/shoot

17 ratio was 0.58 . This corresponds well with López et al. (2013), who reported a root/shoot ratio of 0.56 for Lolium perenne. 

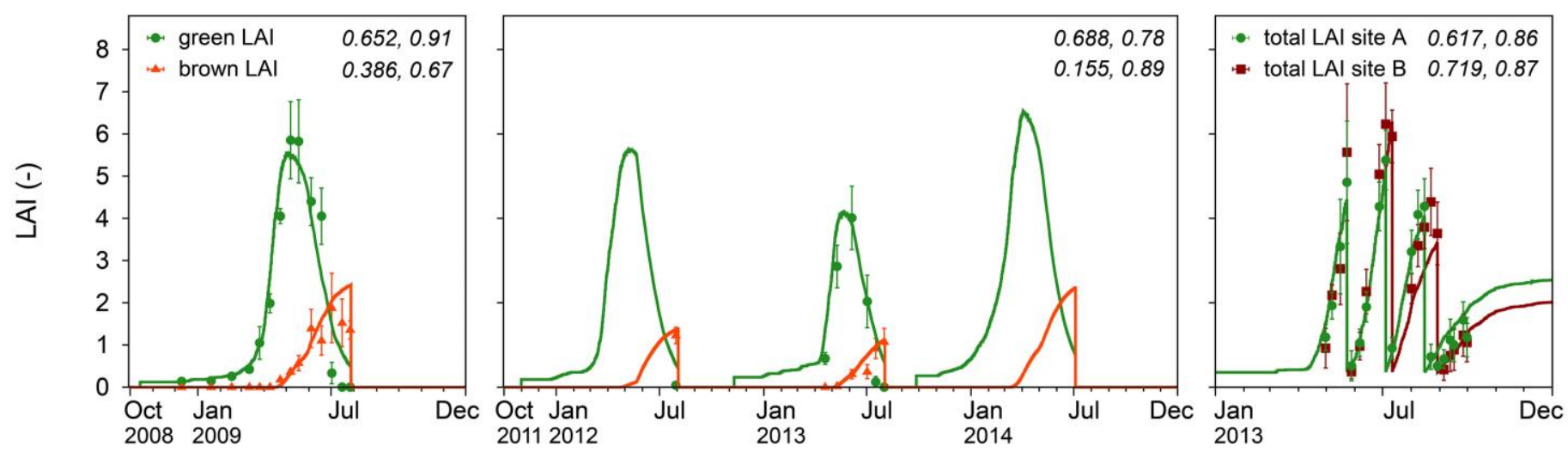

1

2 Fig. 4:

3 Observed (dots; error bars: standard deviation) and simulated (lines) leaf area index (LAI) in

4 Selhausen (left), Merzenhausen (middle), and Rollesbroich (right). For the two cropped fields

5 green and brown LAI were measured and simulated. Root mean square error (RMSE) and

6 model efficiency (ME) (in this order) are given for each quantity and location.

7
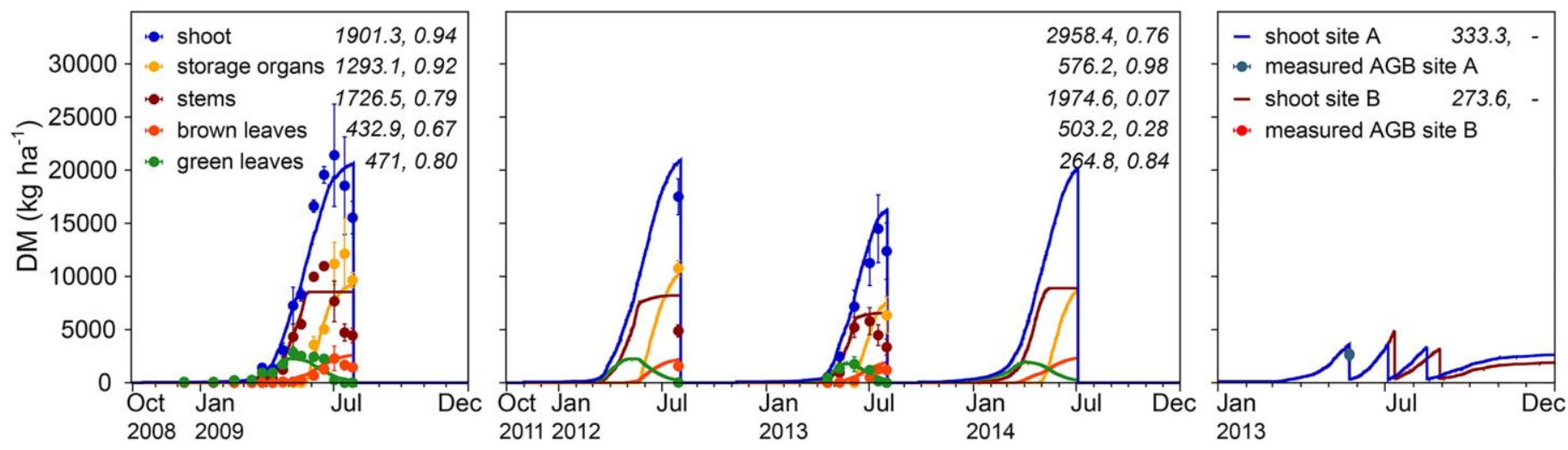

8

9 Fig. 5:

10 Observed (dots; error bars: standard deviation) and simulated (lines) dry matter (DM) in

11 Selhausen (left), Merzenhausen (middle), and Rollesbroich (right; AGB: above-ground

12 biomass). Root mean square error (RMSE) and model efficiency (ME) (in this order) are

13 given for each quantity and location. 


\section{Soil Respiration}

Magnitude and dynamics of soil $\mathrm{CO}_{2}$ efflux were captured adequately by AgroC, as shown by $M E$ values larger than $0.58, R M S E$ values lower than $45.4 \mathrm{~mol} \mathrm{ha}^{-1} \mathrm{~h}^{-1}$, and an $r$ larger than 0.77 across all sites. For the Selhausen site, observations of efflux due to heterotrophic respiration were available separately (Prolingheuer et al., 2014). Therefore, Figure 6 not only shows modeled total respiration, but also the simulated partitioning in root and rhizosphere respiration and heterotrophic respiration. Since this partitioning is available only for the production terms but not for efflux at the surface, the errors reported in Figure 6 differ slightly from those presented above. Parameters of the reduction functions for heterotrophic $\mathrm{CO}_{2}$ production in the soil profile were also calibrated. The start parameter for the reference temperature was set to the annual mean temperature at each site as suggested by Coleman and Jenkinson (2008). In the optimization process, all reference temperatures were decreased, thus $\mathrm{CO}_{2}$ production was increased at any temperature. As reported by Bauer et al. (2012) and Moyano et al. (2012), the approach after Skopp et al. (1990) provided the best results for the response of $\mathrm{CO}_{2}$ production to soil moisture. Therefore, the two control parameters of this response function were calibrated. The estimated optimal water content (maximum of reduction function curve) was $0.41,0.29$, and $0.28 \mathrm{~cm}^{3} \mathrm{~cm}^{-3}$ in Selhausen, Merzenhausen, and Rollesbroich, respectively. The optimum water contents were very close to the mean soil water content of each simulation $\left(0.38,0.29\right.$, and $0.32 \mathrm{~cm}^{3} \mathrm{~cm}^{-3}$, respectively).

As shown in Figure 6, $\mathrm{CO}_{2}$ production at the grassland site was higher than at the cropped sites, which is attributed to the higher soil organic carbon content (Tab. A.1) and an extensive perennial root system. However, the magnitude of the simulated rhizospheric respiration turned out to be quite similar for all sites, even though the grassland accumulates root biomass over the years. The root/shoot ratios reported above showed that the below-ground translocation of assimilated carbon was much higher for grassland than for cereal crops. 
1 Hence, the relative fraction of assimilates partitioned to the root system is larger in grasslands

2 (Kuzyakov and Domanski, 2000). Considering the same growth period, the absolute

3 translocation of carbon is the same for both ecosystems; whilst cereals have a higher

4 productivity per unit area and time, their carbon assimilation is restricted to a shorter growth

5 period compared to grasslands. Further, grasslands are not ploughed, so they are potentially a

6 larger sink for atmospheric carbon (Kuzyakov and Domanski, 2000).

7 An extensive peak of soil $\mathrm{CO}_{2}$ emission was simulated right after harvest of the cereals, 8 because a large amount of fresh plant material was added to the carbon pools of the soil.

9 Unfortunately, no chamber-based $\mathrm{R}_{\text {soil }}$ observations were available for those critical time 10 periods to validate these model predictions.

11 The estimated mean annual ratio between rhizospheric respiration and total $\mathrm{R}_{\text {soil }}$ was 0.12 for 12 Selhausen, 0.21 for Merzenhausen, and 0.34 for Rollesbroich. Wang and Fang (2009) analyzed 36 grassland sites and reported a corresponding average ratio of 0.36 , which agrees well with results for our grassland site in Rollesbroich. For winter wheat, Moureaux et al. (2008) obtained a ratio between below-ground respiration by autotrophs and total $R_{\text {soil }}$ of 0.56 for the vegetation period only. Suleau et al. (2011) found ratios between 0.40 and 0.48 using root exclusion experiments. The simulated ratios for the vegetation period were 0.18 for Selhausen and between 0.33 and 0.38 for Merzenhausen. It seems that the simulated fraction of rhizospheric respiration in Selhausen is too low compared to previous studies. However, these values were confirmed by measurements from root exclusion experiments at this site 21 (Prolingheuer et al., 2014). Subke et al. (2006) compared numerous respiration ratios derived by various methods from several studies, and report that the heterotrophic source term may be overestimated by root exclusion, because of increased dead root biomass (for experiments conducted within perennial vegetation), a change of irradiation, and a decreased water uptake by roots. In our study, those error sources were mostly excluded, due to installation of the 
1 exclusion rings before cereal growth, a small ring size that enables representative growth and

2 shading around/above the measurement points, and the correction for the soil moisture effects 3 (Prolingheuer et al., 2014).

4 For Rollesbroich, measurements of soil $\mathrm{CO}_{2}$ concentration in different depths were available,

5 which allowed calibration of the $\mathrm{CO}_{2}$ flux through the soil. The approach after Kristensen et 6 al. (2010), which additionally accounts for diffusion through fractures and macropores, 7 provided the best results with a $M E$ of 0.44 (Fig. 7). 

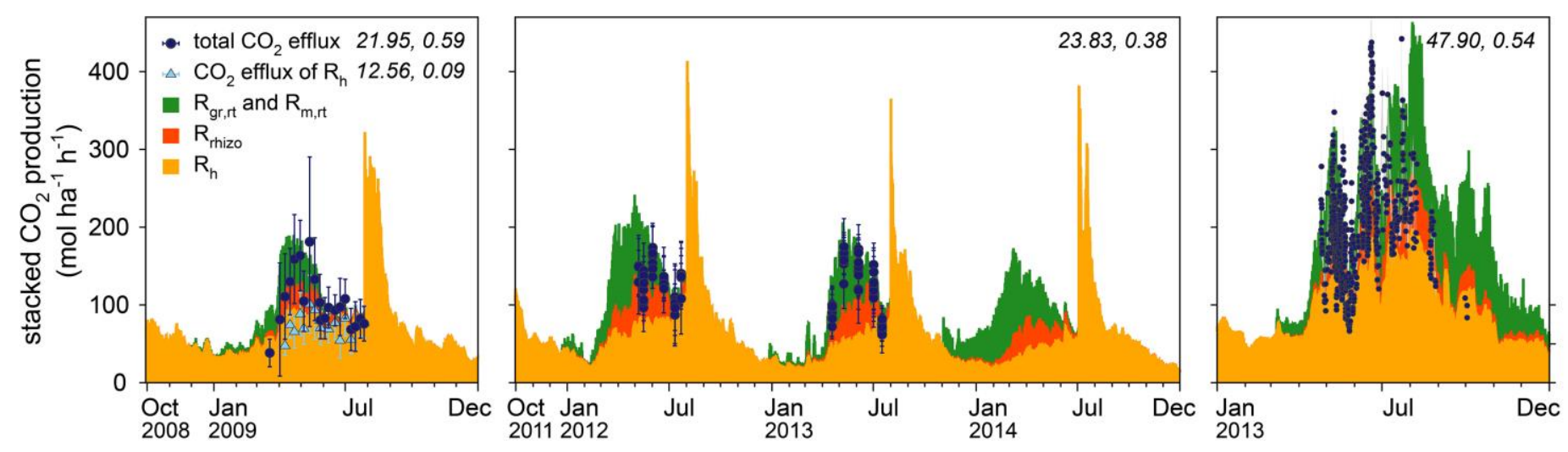

2 Fig. 6:

3 Observed (dots; error bars: standard deviation) $\mathrm{CO}_{2}$ efflux at soil surface and simulated 4 stacked $\mathrm{CO}_{2}$ production in soil profile (areas) for several source terms (green: growth and 5 maintenance respiration by roots $\left(\mathrm{R}_{\mathrm{gr}, \mathrm{rt}}, \mathrm{R}_{\mathrm{m}, \mathrm{rt}}\right)$; orange: respiration in rhizosphere $\left(\mathrm{R}_{\text {rhizo }}\right)$ due to 6 root exudates and root decay; yellow: respiration by heterotrophs $\left(\mathrm{R}_{\mathrm{h}}\right)$ ) in Selhausen (left), 7 Merzenhausen (middle), and Rollesbroich (parcel A, right). Root mean square error (RMSE) 8 and model efficiency (ME) (in this order) are given for each location.

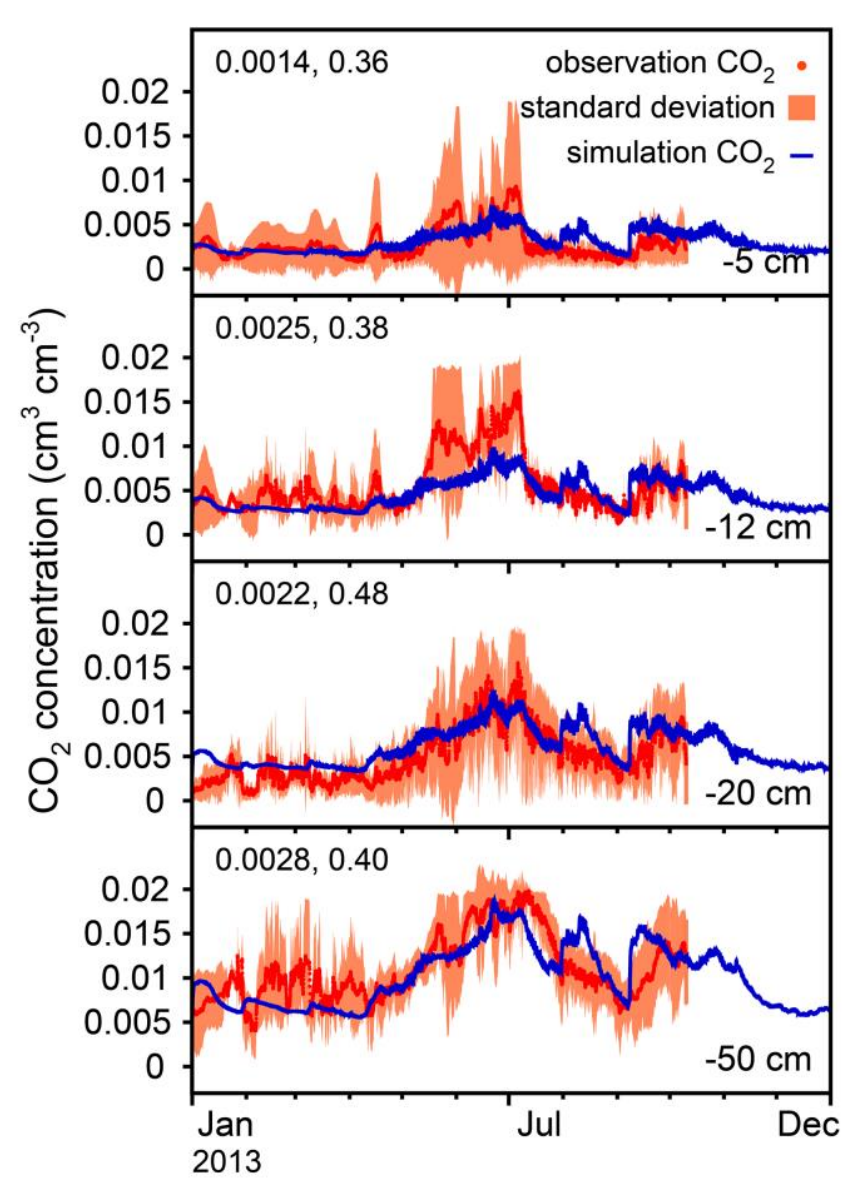

Fig. 7:

Observed (dots; orange area: standard deviation) and simulated (lines) soil $\mathrm{CO}_{2}$ concentration at various depths in Rollesbroich. Root mean square error (RMSE) and model efficiency (ME) (in this order) are given for each soil depth. 
Net Ecosystem Exchange

After calibrating soil water flux, plant development, and $\mathrm{CO}_{2}$ flux, we compared the NEE simulations to the EC measurements at each test site. At this point, NEE measurements were not used to calibrate the model. Figure 8 and 9 show the AgroC estimates in comparison to the NEE flux measurements. With a RMSE between 113 and $128 \mathrm{~mol} \mathrm{ha}^{-1} \mathrm{~h}^{-1}$, a $M E$ between 0.78 and 0.83 , and an $r$ between 0.91 and 0.96 , AgroC performed reasonably well at all three test sites. However, some discrepancies could also be observed. As already discussed for $\mathrm{R}_{\text {soil }}$, the estimated peaks of $\mathrm{R}_{\text {soil }}$ and corresponding NEE after harvest were also not observed in the EC measurements (Fig. 8). Fluxes from adjacent and cropped fields could have distorted the measurements of the area of interest (e.g., Massman and Lee, 2002). In Merzenhausen in autumn 2012, negative $\mathrm{CO}_{2}$ fluxes were measured even though the crop was harvested. This was not captured by the AgroC model, because it was assumed that the field was bare fallow. In reality, weeds and wheat emerged again during this post-harvest period and assimilated $\mathrm{CO}_{2}$ until ploughing (cf., Sus et al., 2010).

At the Rollesbroich site, the EC tower was located at the border between two differently managed grassland parcels, so that the contribution of $\mathrm{CO}_{2}$ fluxes originating from each of the two parcels varied according to the flux footprint (Kormann and Meixner, 2001; Mauder et al., 2013; Post et al., 2015). For validation, two AgroC model runs were made for grassland parcels A and B. The two NEE estimates were weighted according to the relative fraction of the footprint within each parcel, and subsequently compared to the observations. Consequently, simulated fluxes could only be attained for time steps at which measurements and thus information about the footprint distribution were available. The consideration of the footprint distribution improved the performance of the NEE simulations significantly compared to a single model run. This was especially true for time periods between two mowing events, since parcel B was always mown a few days later than parcel A. Generally, 
1 AgroC reproduced the dynamics of the grassland NEE including the effect of mowing and regrowth. At the time of mowing, leaf area was reduced substantially, canopy photosynthesis decreased, and the site temporarily turned from a $\mathrm{CO}_{2}$ sink to a $\mathrm{CO}_{2}$ source. From the first to the third mowing, peak assimilation declined consistently. This has previously also been reported for other grassland sites (Schmitt et al., 2010; Wohlfahrt et al., 2008).

The ratios between the annual sum of TER and GPP were 0.79 for Selhausen, between 0.67 and 0.75 for Merzenhausen, and 1.06 for Rollesbroich. The ratios for the growing period only were 0.64 for Selhausen and between 0.52 and 0.62 for Merzenhausen. The value higher than 1 for Rollesbroich indicates that this site was a $\mathrm{CO}_{2}$ source in 2013. The annual ratios between respiration by heterotrophs and TER varied between 0.51 and 0.58 (ratios for growing period: 0.35 - 0.48). Moureaux et al. (2008) and Suleau et al. (2011) report TER/GPP ratios between 0.49 and 0.66 for cereals, and $R_{h} /$ TER ratios between 0.2 and 0.24 , again only considering the plant growth phase. Our simulations generally agree well with these values, although the heterotrophic component appears to be larger in this study. Again, this reflects the lower contribution of rhizospheric respiration as already discussed above.

The 1:1 plots between observed and simulated NEE (Fig. 9) show that on average AgroC overestimated the $\mathrm{CO}_{2}$ fluxes by less than $20 \%$, since the regression lines fall within the grey area. Turbulence fluxes can be systematically underestimated by EC measurements, and energy balance closure gaps of this magnitude have previously been reported (Eder et al., 2015; Schmidt et al., 2012; Twine et al., 2000). Therefore, underestimation of $\mathrm{CO}_{2}$ fluxes can be expected (Ingwersen et al., 2015; Massman and Lee, 2002; Mauder et al., 2013). This inability to close the surface energy balance, the various approaches to correct for the balance gaps, uncertainties due to instrumentation, and differing data-processing strategies complicate cross-site and long-term comparisons of NEE (Massman and Lee, 2002; Mauder et al., 2013; Schmidt et al., 2012; Twine et al., 2000). 
1 Wattenbach et al. (2010) compared the efficiency of four models to simulate NEE, and 2 reported $M E$ values between -0.15 and 0.87 . The $M E$ values for AgroC for the three sites 3 compare favorably with this wide range $(0.78-0.83)$. Wattenbach et al. (2010) also reported 4 more substantial discrepancies between observations and simulations for positive NEE fluxes. 5 Such an underestimation of positive NEE fluxes was also observed in this study, but to a 6 much smaller extent, which is very likely a result of our more advanced approach towards the 7 simulation of $\mathrm{CO}_{2}$ fluxes and the calibration of $\mathrm{R}_{\text {soil }}$ with chamber measurements. 

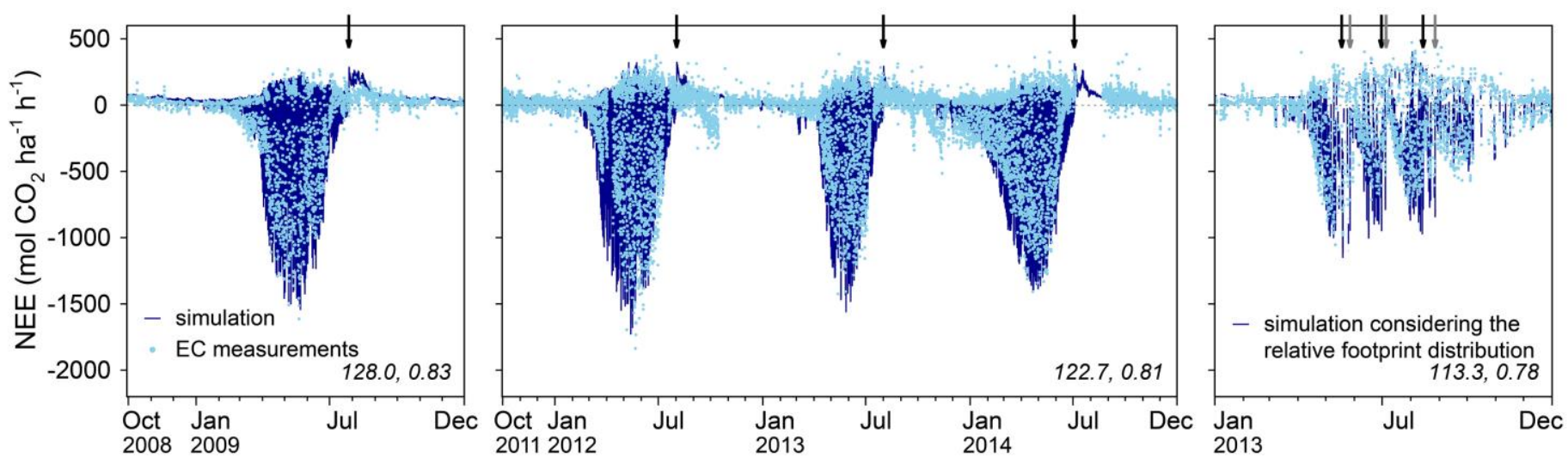

1

2 Fig. 8:

3 Observed (dots) and simulated (lines) net ecosystem exchange (NEE) in Selhausen (left; EC:

4 eddy covariance), Merzenhausen (middle), and Rollesbroich (right). In Rollesbroich NEE was

5 simulated for each grassland (parcel A and B) and then allocated with the relative fraction of

6 the footprint on each grassland. Arrows indicate dates of harvest or mowing (black: parcel A;

7 grey: parcel B), respectively. Root mean square error (RMSE) and model efficiency (ME) (in

8 this order) are given for each location.

9
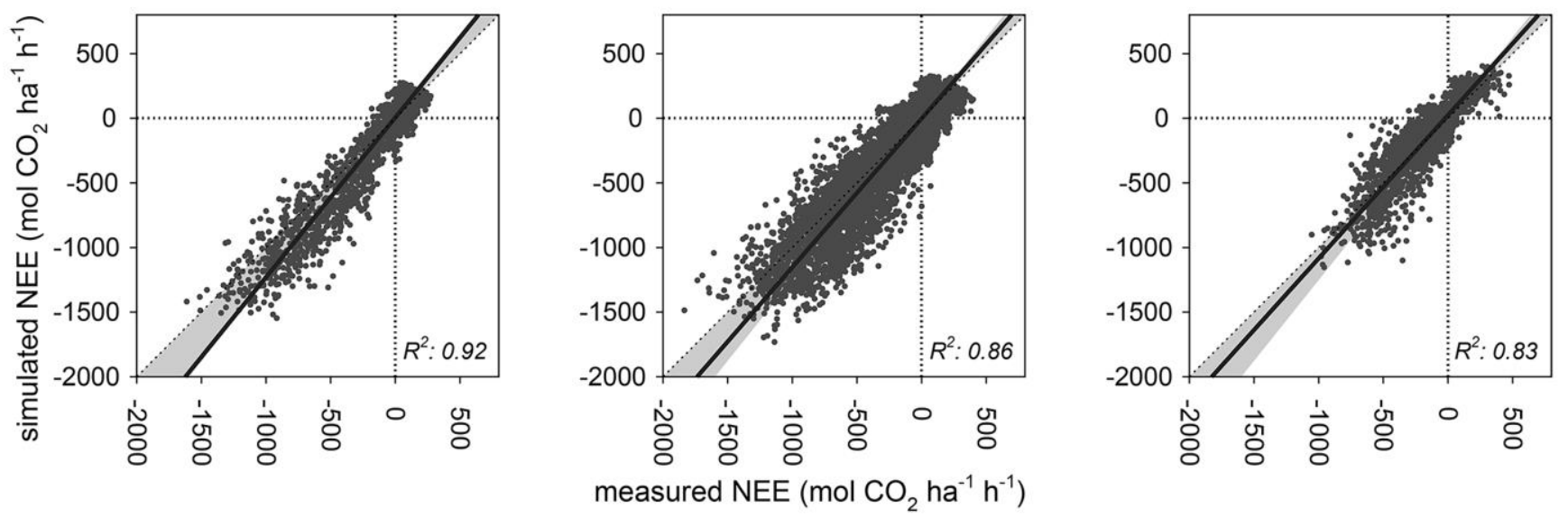

10

11 Fig. 9:

12 Observed and simulated net ecosystem exchange (NEE) with regression line (black) in

13 Selhausen (left), Merzenhausen (middle), and Rollesbroich (right). In Rollesbroich NEE was

14 simulated for each grassland (parcel A and B) and then weighted according to the relative

15 fraction of the footprint. A potential NEE gap of up to $20 \%$ in the measurements is indicated

16 by the grey area. Coefficient of determination $\left(\mathrm{R}^{2}\right)$ is given for each location. 


\subsection{Calibration with NEE Data}

After calibration to NEE measurements, the RMSE was reduced by up to $43 \%$, and Bias also decreased strongly (Fig. 10). Depending on the optimization strategy, the cumulative NEE over the simulation period differed strongly (Fig. 10, B.3). The calibration based on the instantaneous NEE data $\left(N E E_{\text {inst }}\right)$ yielded the best results in terms of $R M S E, M E$, and $r$ at all sites, because the reduction of the squared residual error between NEE prediction and measurements was the only criterion. Bias was the lowest in the $N E E_{B S c}$ approach with and without inclusion of $\mathrm{R}_{\text {soil }}$ data because the Bias was now part of the objective function. Apart from that, model performance and NEE prediction by the $N E E_{B S c}\left(+R_{\text {soil }}\right)$ approach were very similar to $N E E_{\text {inst }}\left(+R_{\text {soil }}\right)$. The $N E E_{\text {Cum }}$ and $N E E_{\text {Log }}+R_{\text {soil }}$ approaches resulted in the poorest model performances at each study site. In almost all cases, model performance for NEE slightly deteriorated when $\mathrm{R}_{\text {soil }}$ measurements were included in the optimization process due to trade-offs between fitting multiple objective functions, with the exception of the approach that considered $N E E_{C u m}+R_{\text {soil }}$ (Fig. 10).

Figure 11 shows reduced major axis regression (Webster, 1997) for measured and simulated day- and nighttime (nighttime hours with global radiation $<20 \mathrm{~W} \mathrm{~m}^{-2}$ after Reichstein et al., 2005) NEE fluxes for the test site Selhausen. The corresponding figures for Merzenhausen and Rollesbroich are given in the appendix (Fig. B.1, B.2). Compared to the NEE predictions obtained without calibration (Fig. 9), the calibrated daytime fluxes were generally closer to the 1:1 line and tended to only slightly underestimate daytime NEE fluxes as indicated by regression slopes slightly lower than 1 . In general, nighttime NEE fluxes (dominated by respiratory fluxes) were better captured by the approaches that used an objective function including $\mathrm{R}_{\text {soil }}$ data, irrespective of the error weighting in the objective function or the transformation of the raw NEE data. Including $\mathrm{R}_{\text {soil }}$ data in the calibration clearly improved the simulation of diurnal and annual dynamics of the measured $\mathrm{R}_{\text {soil }}$. The approaches only 
1 considering NEE measurements did not reproduce those dynamics (not shown). Even with the

2 inclusion of $\mathrm{R}_{\text {soil }}$ data, nighttime NEE was still underestimated as indicated by regression 3 slopes between 0.75 and 0.85 (Fig. 11, B.1, B.2).

4 In Figure 10 (bottom right panel) and in the appendix (Fig. B.3), cumulative NEE over the 5 corresponding simulation period (referred to as "cumulative NEE" in the following) is shown 6 for all optimization strategies, for the simulations without calibration, and for the gap-filling 7 method by Reichstein et al. (2005). For this comparison, cumulative NEE estimated with AgroC was also calculated in a "gap-filling mode", keeping the EC measurements and only

9 filling the gaps with AgroC results. The cumulative NEE varied between -462 and $-243 \mathrm{~g} \mathrm{C} \mathrm{m}^{-2}$ in Selhausen, -1429 and $-1180 \mathrm{~g} \mathrm{C} \mathrm{m}^{-2}$ in Merzenhausen, and -541 and $-5 \mathrm{~g} \mathrm{C} \mathrm{m}^{-2}$ in Rollesbroich. Cumulative NEE was mostly lower for the calibrated model runs than for the uncalibrated simulation. For all sites, the $N E E_{C u m}$ or $N E E_{L o g}$ approach with and without $\mathrm{R}_{\text {soil }}$ measurements resulted in the lowest cumulative NEE. The $N E E_{\text {inst }}+R_{\text {soil }}$ approach resulted in the highest NEE, except for the Rollesbroich site. Generally, cumulative NEE of approaches including $R_{\text {soil }}$ data in the objective function showed better agreement with the gap-filling method after Reichstein et al. (2005) than the approaches that did not consider $\mathrm{R}_{\text {soil }}$ measurements (Fig. 10).

Neglecting carbon removal due to harvest, the simulations suggest that all sites are $\mathrm{CO}_{2}$ sinks, except for the simulation without calibration to NEE in Rollesbroich, which showed a very small positive annual NEE. Pastures are usually considered to be sinks for atmospheric $\mathrm{CO}_{2}$

21 (Kuzyakov and Domanski, 2000). Soussana et al. (2007) estimated an average annual carbon budget of $-247 \pm 67 \mathrm{~g} \mathrm{C} \mathrm{m}^{-2}$ and a net biome productivity (= NEE minus carbon loss due to disturbances, such as harvest) of $-104 \pm 73 \mathrm{~g} \mathrm{C} \mathrm{m}^{-2}$ for nine grasslands in Europe. Wohlfahrt et al. (2008) reported alternating positive and negative annual NEE for one grassland (gapfilled EC measurements), varying between $-42 \mathrm{~g} \mathrm{C} \mathrm{m}^{-2} \mathrm{a}^{-1}$ and $69 \mathrm{~g} \mathrm{C} \mathrm{m}^{-2} \mathrm{a}^{-1}$, and concluded 
1 that meteorological variations or differing biotic responses could easily lead to a positive

2 carbon balance in some years. Also, the large amount of carbon stored in grassland soils

3 (Tab. A.1) can easily cause large respiratory fluxes that exceed plant carbon uptake. For

4 Selhausen, estimated NEE matches cumulative values reported by Schmidt et al. (2012) and

5 Wattenbach et al. (2010). Anthoni et al. (2004) found annual NEE in a range from -185

6 to $-245 \mathrm{~g} \mathrm{C} \mathrm{m}^{-2}$ for a winter wheat field in Germany in 2001, which is in good agreement with

7 our findings.

8 Since the true cumulative NEE is unknown due to measurement gaps, modelling can provide

9 valuable information about the carbon balance. The best calibration approach that provides

10 the 'true' cumulative NEE cannot be determined at this point. However, our results suggest

11 that the cumulative NEE obtained from the calibrated model runs is more realistic than the

12 cumulative NEE obtained with a model run not calibrated to NEE. The well-established gap-

13 filling method after Reichstein et al. (2005) and AgroC produced somewhat different carbon

14 balances, although NEE was derived from the same weather data. Especially after harvest or

15 mowing, AgroC provided more reasonable predictions because it considers the changes in

16 crop characteristics that directly influence GPP. Nevertheless, a better representation of

17 respiration processes is still required, because even after calibration with EC and chamber measurements the respiration by heterotrophs and autotrophs was still underestimated. This bias between measured and modelled respiration may indicate a wrong process representation in the model, errors in model parameterization, or may also be related to a disparity in the

21 measurement footprint between chamber and EC measurements (Richardson et al., 2010).

22 Obviously, an underestimation of respiratory fluxes will shift NEE to more negative values, 23 as observed for the simulation results in Figure 10.

24 The cumulative NEE obtained after calibration with EC measurements was sensitive to the 25 definition of the objective function and the data-transformation. As expected, explicit 
1 consideration of Bias in the objective function reduced the Bias substantially (Fig. 10), with

2 the $N E E_{B S c}$ approach being most effective. The $N E E_{C u m}$ approach often led to overestimation

3 of negative and underestimation of positive fluxes (Fig. 10, 11, B.1, B.2). The use of

4 cumulative data is known to enhance systematic errors and reduce noise (Hess and Schmidt,

5 1995; Mandel, 1957), and might not provide statistically valid information about associated

6 errors and results if non-random auto-correlated residuals prevail. Compared to using the Bias

7 as a criterion, it gives more weight to early observations that affect all succeeding cumulative

8 values in the simulation period.

9 High-quality (hourly) EC measurements obtained after data processing usually consist of a

10 large number of large negative fluxes during daytime and a smaller number of small positive

11 nighttime fluxes, the latter being underrepresented. During calibration, the negative fluxes

12 will on average have a higher weight, since they are more frequent and larger than positive

13 fluxes. Therefore, a log-transformation of the NEE data could partly compensate for this, and

14 provide more equal weighting. However, our results suggest the effect of this transformation

15 on the performance of the calibration was weak. The slope of the regression between observed

16 and simulated positive NEE was just slightly closer to 1 for the $N E E_{L o g}\left(+R_{\text {soil }}\right)$ approach

17 (Fig. 11, B.1, B.2).

18 The model performance for small positive fluxes improved strongly when considering $\mathrm{R}_{\text {soil }}$

19 measurements as an additional data source (Fig. 11, B.1, B.2). Similar findings were reported

20 by Richardson et al. (2010), Wang et al. (2009), and Yuan et al. (2012). Williams et al. (2009)

21 stated that the use of multiple data streams in calibration reduces the sensitivity to biases and

22 internal inconsistencies in each data stream. Including $\mathbf{R}_{\text {soil }}$ measurements in the optimization

23 process notably reduced the bias in the simulated nighttime NEE more than any of the

24 modifications of the objective function or the use of data-transformation. 
1 The $N E E_{\text {inst }}+R_{\text {soil }}$ approach provided the best results regarding both day- and nighttime

2 fluxes at all three test sites. On average, model bias was one of the lowest for this 3 optimization strategy at all sites. Even though overall model performance of the eight

4 calibration approaches differed only marginally, it was found that resulting cumulative NEE 5 diverged strongly. Considering additional data sources such as biomass measurements should 6 help to further decrease the uncertainty of the cumulative NEE estimation (Richardson et al., 7 2010). 

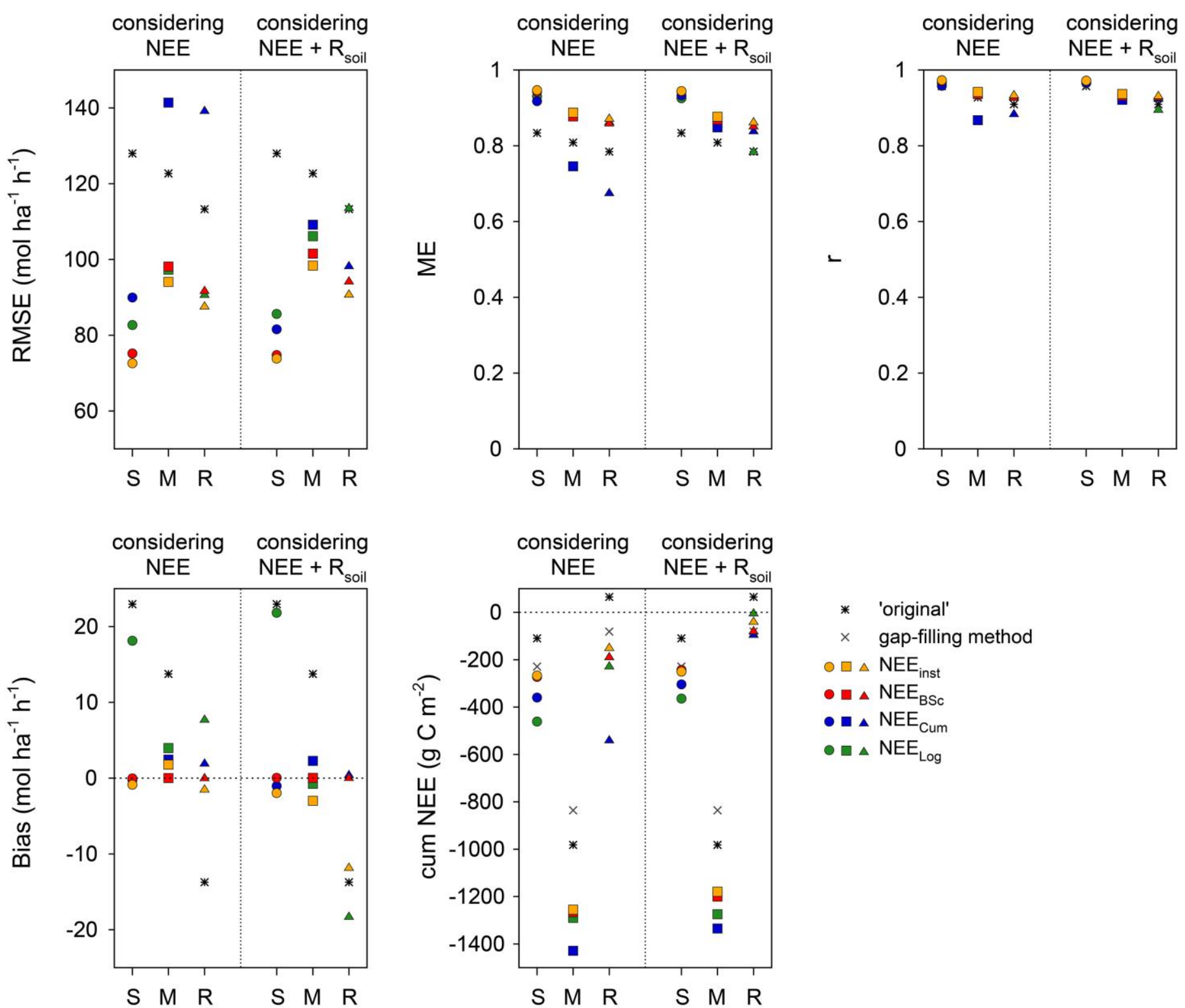

2 Fig. 10:

3 Root mean square error (RMSE), model efficiency (ME), Pearson product-moment 4 correlation coefficient (r), Bias, and cumulated net ecosystem exchange (cum NEE) over 5 simulation time period, calculated in "gap-filling mode", for each optimization strategy, for 6 the simulation without calibration to NEE ('original'), and for the gap-filling method after 7 Reichstein et al. (2005) (gap-filling method) at all three study sites (S: Selhausen; M:

8 Merzenhausen; R: Rollesbroich). For description of optimization strategies see text. 

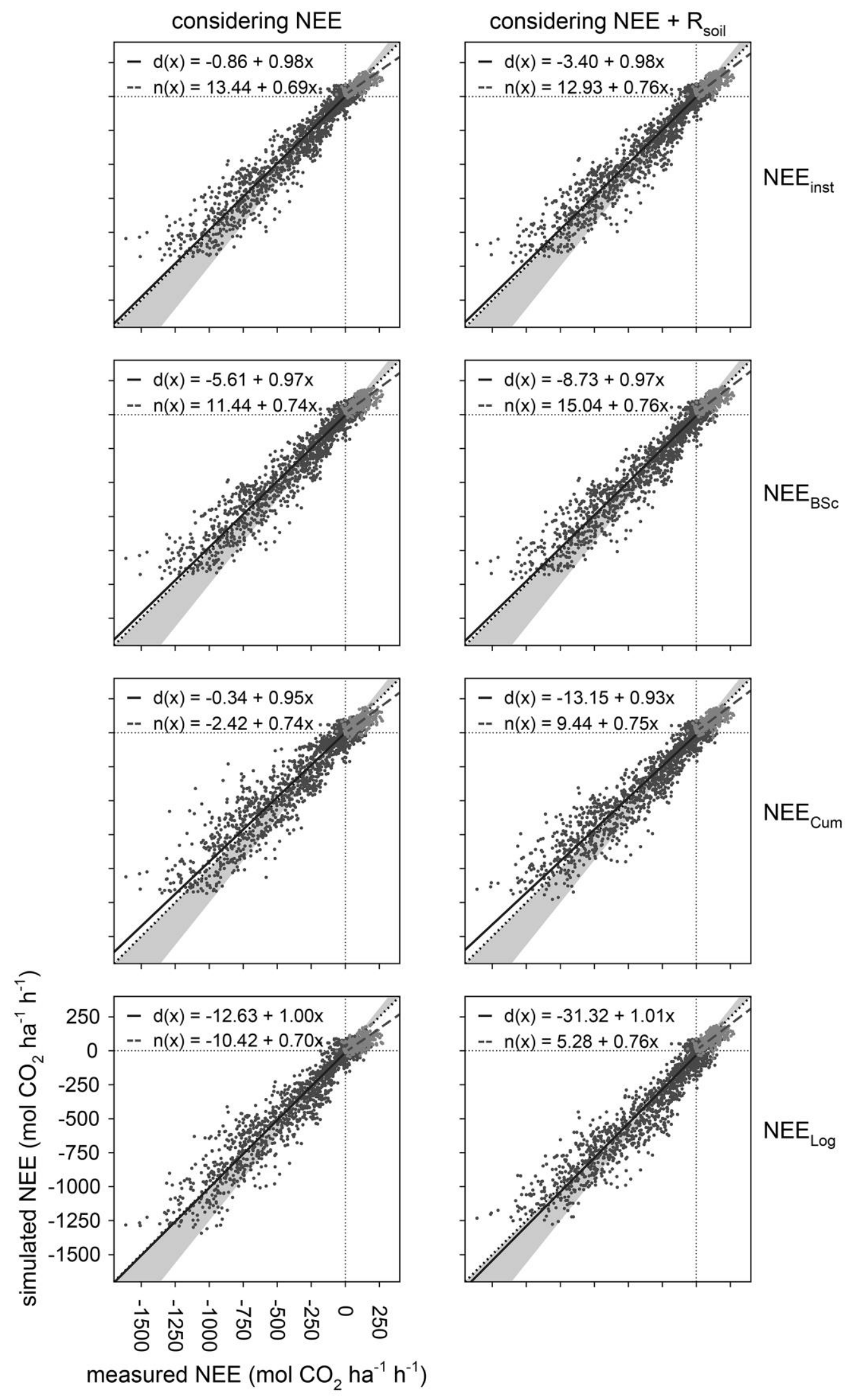

1 Fig. 11:

2 Correlations between observed and simulated net ecosystem exchange (NEE) for all 3 optimization strategies at test site Selhausen. Reduced major axis regression was derived for 4 each strategy distinguished between day- (d) and nighttime (n) $\mathrm{CO}_{2}$ fluxes, whereat nighttime 5 was designated to a measured global radiation lower than $20 \mathrm{~W} \mathrm{~m}^{-2}$. For description of 6 optimization strategies see text. 


\section{4. Conclusions}

2 The present study demonstrates that a crop growth module coupled to a model of soil $\mathrm{CO}_{2}$ 3 production, soil water and heat flux can be used to simulate hourly NEE in agricultural 4 systems. After calibrating the model for soil moisture, crop development, and $\mathrm{R}_{\text {soil }}$, the 5 simulation of hourly NEE agreed well to EC measurements. For further validation, the 6 application of AgroC to cropping systems in different European climate regions would be 7 interesting.

8 An additional calibration based on EC measurements further improved the model in terms of

9 the performance criteria. Even more importantly, systematic errors between EC data and model were reduced. However, the various calibration approaches reveal that particularly the

11 cumulative NEE over the entire simulation period is rather strongly affected by the choice of 12 the objective criterion. Based on the evaluation of different optimization strategies, we recommend the use of the RMSE and non-transformed instantaneous EC-derived fluxes in combination with $\mathrm{R}_{\text {soil }}$ measurements (if available) by equally weighted errors. Our results indicate that cumulative NEE obtained using calibration and gap-filling-methods is associated with considerable uncertainty, which can be decreased when $\mathrm{R}_{\text {soil }}$ measurements are included in the optimization process. At the same time, inclusion of $\mathbf{R}_{\text {soil }}$ also provided a substantial reduction of bias in the simulation of the respiratory fluxes.

\section{Acknowledgements}

21 This research was supported by FACCE MACSUR - Modelling European Agriculture with 22 Climate Change for Food Security and by the German Federal Ministry of Education and 23 Research BMBF, project IDAS-GHG [grant number 01LN1313A]. The measurement 24 infrastructure providing observational data was supported by the German Research 25 Foundation DFG through the Transregional Collaborative Research Centre 32 (TR 32) and 
1 Terrestrial Environmental Observatories (TERENO). We thank Axel Knaps (Sicherheit und

2 Strahlenschutz - Umwelt, Meteorologie (S-UM), Forschungszentrum Jülich GmbH) for

3 providing climate information, Ludger Bornemann (Institute of Crop Science and Resource

4 Conservation (INRES) - Division of Soil Science, University of Bonn) for the analysis of

5 black carbon, Henning Schiedung (INRES - Division of Soil Science, University of Bonn) for

6 providing soil carbon fractions. The authors thank all technicians, engineers, and laboratory

7 assistants in TR32 and TERENO for providing measurements of the test sites. We are also

8 grateful to Daniel Farber and Horst Hardelauf for modifications of the model source code.

9 Finally, we thank the reviewers for their helpful comments that improved the quality of this

10 manuscript. 


\section{$1 \quad$ References}

2 Allen, R.G., Pereira, L.S., Raes, D., Smith, M., 1998. Crop Evapotranspiration. Guidelines for computing crop water requirements. FAO Irrigation and Drainage Paper No. 56. Food and Agriculture Organization of the United Nations (FAO), Rome. 300 pp.

Anslow, R.C., Green, J.O., 1967. The seasonal growth of pasture grasses. J Agr Sci 68, 109-122.

Anthoni, P.M., Freibauer, A., Kolle, O., Schulze, E.-D., 2004. Winter wheat carbon exchange in Thuringia, Germany. Agr Forest Meteorol 121 (1-2), 55-67. http://dx.doi.org/10.1016/S0168-1923(03)00162-X.

Baldocchi, D.D., 2003. Assessing the eddy covariance technique for evaluating carbon dioxide exchange rates of ecosystems: past, present and future. Glob Change Biol 9 (4),

Barrett, P.D., Laidlaw, A.S., Mayne, C.S., 2004. An evaluation of selected perennial ryegrass growth models for development and integration into a pasture management decision support system. J Agr Sci 142, 327-334. http://dx.doi.org/10.1017/s0021859604004289.

Bauer, J., Herbst, M., Huisman, J.A., Weihermüller, L., Vereecken, H., 2008. Sensitivity of simulated soil heterotrophic respiration to temperature and moisture reduction functions. Geoderma 145 (1-2), 17-27. http://dx.doi.org/0.1016/j.geoderma.2008.01.026.

Bauer, J., Weihermüller, L., Huisman, J.A., Herbst, M., Graf, A., Séquaris, J.-M., Vereecken, H., 2012. Inverse determination of heterotrophic soil respiration response to temperature and water content under field conditions. Biogeochemistry 108 (1-3), 119-134. http://dx.doi.org/10.1007/s10533-011-9583-1.

Bolinder, M.A., Angers, D.A., Dubuc, J.P., 1997. Estimating shoot to root ratios and annual carbon inputs in soils for cereal crops. Agr Ecosyst Environ 63 (1), 61-66. http://dx.doi.org/10.1016/s0167-8809(96)01121-8. 
1 Bolinder, M.A., Angers, D.A., Bélanger, G., Michaud, R., Laverdière, M.R., 2002. Root

2 biomass and shoot to root ratios of perennial forage crops in eastern Canada. Can J Plant $3 \quad$ Sci $82(4), 731-737$.

4 Boons-Prins, E.R., de Koning, G.H.J., van Diepen, C.A., Penning de Vries, F.W.T., 1993.

5 Crop-specific simulation parameters for yield forecasting across the European Community.

6 Simulation Reports CABO-TT, no 32. CABO-DLO, Wageningen. 43 pp.

7 Borchard, N., Schirrmann, M., von Hebel, C., Schmidt, M., Baatz, R., Firbank, L., Vereecken, H., Herbst, M., 2015. Spatio-temporal drivers of soil and ecosystem carbon fluxes at field

scale in an upland grassland in Germany. Agr Ecosyst Environ 211, 84-93. http://dx.doi.org/10.1016/j.agee.2015.05.008.

Coleman, K., Jenkinson, D.S., 2008. RothC-26.3. A model for the turnover of carbon in soil. Model description and windows users guide. IACR-Rothamsted, Harpenden. 47 pp.

de Noblet-Ducoudré, N., Gervois, S., Ciais, P., Viovy, N., Brisson, N., Seguin, B., Perrier, A., 2004. Coupling the Soil-Vegetation-Atmosphere-Transfer Scheme ORCHIDEE to the agronomy model STICS to study the influence of croplands on the European carbon and water budgets. Agronomie 24 (6-7), 397-407. http://dx.doi.org/10.1051/agro:2004038.

Duan, Q.Y., Gupta, V.K., Sorooshian, S., 1993. Shuffled Complex Evolution Approach for Effective and Efficient Global Minimization. J Optimiz Theory App 76 (3), 501-521. http://dx.doi.org/10.1007/bf00939380.

Eder, F., Schmidt, M., Damian, T., Traumner, K., Mauder, M., 2015. Mesoscale eddies affect near-surface turbulent exchange: evidence from Lidar and tower measurements. J Appl Meteor Climatol 54 (1), 189-206. http://dx.doi.org/10.1175/JAMC-D-14-0140.1.

Evans, G.T., 2003. Defining misfit between biogeochemical models and data sets. J Marine Syst 40-41, 49-54. http://dx.doi.org/10.1016/s0924-7963(03)00012-5. 
1 Falloon, P., Smith, P., Coleman, K., Marshall, S., 1998. Estimating the size of the inert

2 organic matter pool from total soil organic carbon content for use in the Rothamsted

3 carbon model. Soil Biol Biochem 30 (8-9), 1207-1211.

4 http://dx.doi.org/10.1016/s0038-0717(97)00256-3.

5 Feddes, R.A., Kowalik, P.J., Zaradny, H., 1978. Simulation of field water use and crop yield.

$6 \quad$ Simulation Monographs, Wageningen, 188 pp.

7 Food and Agriculture Organization (FAO) of the United Nations, Regional Office for Europe and Central Asia, 2014. FAO Statistical Yearbook 2014. Europe and Central Asia, Food and Agriculture. FAO, Budapest, 113 pp.

Gebler, S., Hendricks Franssen, H.J., Pütz, T., Post, H., Schmidt, M., Vereecken, H., 2015. Actual evapotranspiration and precipitation measured by lysimeters: a comparison with eddy covariance and tipping bucket. Hydrol Earth Syst Sci 19 (5), 2145-2161. http://dx.doi.org/10.5194/hess-19-2145-2015.

Gonzales, B., Boucaud, J., Salette, J., Langlois, J., Duyme, M., 1989. Changes in stubble carbohydrate content during regrowth of defoliated perennial ryegrass (Lolium perenne L.) on two nitrogen levels. Grass Forage Sci 44 (4), 411-415. http://dx.doi.org/10.1111/j.1365-2494.1989.tb01940.x.

Goudriaan, J., van Keulen, H., van Laar, H.H., 1997. Crop growth model for potential production (SUCROS1), in: van Laar, H.H., Goudriaan, J., van Keulen, H. (Eds.), SUCROS97: Simulation of crop growth for potential and water-limited production situations. As applied to spring wheat. Quantitative Approaches in Systems Analysis, AB-DLO, Wageningen, pp. 1-20.

Graf, A., Werner, J., Langensiepen, M., van de Boer, A., Schmidt, M., Kupisch, M., Vereecken, H., 2013. Validation of a minimum microclimate disturbance chamber for net 
1 ecosystem flux measurements. Agr Forest Meteorol 174-175, 1-14.

2 http://dx.doi.org/10.1016/j.agrformet.2013.02.001.

3 Herbst, M., Fialkiewicz, W., Chen, T., Pütz, T., Thiéry, D., Mouvet, C., Vachaud, G.,

4 Vereecken, H., 2005. Intercomparison of flow and transport models applied to vertical

5 drainage in cropped lysimeters. Vadose Zone J 4 (2), 240-254.

6 http://dx.doi.org/10.2136/vzj2004.0070.

7 Herbst, M., Hellebrand, H.J., Bauer, J., Huisman, J.A., Šimůnek, J., Weihermüller, L., Graf,

8 A., Vanderborght, J., Vereecken, H., 2008. Multiyear heterotrophic soil respiration:

9 Evaluation of a coupled $\mathrm{CO}_{2}$ transport and carbon turnover model. Ecol Model 214 (2-4),

10 271-283. http://dx.doi.org/10.1016/j.ecolmodel.2008.02.007.

11 Hess, T.F., Schmidt, S.K., 1995. Improved procedure for obtaining statistically valid

12 parameters estimates from soil respiration data. Soil Biol Biochem 27 (1), 1-7.

13 http://dx.doi.org/10.1016/0038-0717(94)00166-X.

14 Hopkins, F., Gonzalez-Meler, M.A., Flower, C.E., Lynch, D.J., Czimczik, C., Tang, J., Subke, 15 J.-A., 2013. Ecosystem-level controls on root rhizosphere respiration. New Phytol 199 (2), 16 339-351. http://dx.doi.org/10.1111/nph.12271.

17 Ingwersen, J., Imukova, K., Högy, P., Streck, T., 2015. On the use of the post-closure 18 methods uncertainty band to evaluate the performance of land surface models against eddy 19 covariance flux data. Biogeosciences 12 (8), 2311-2326.

20 http://dx.doi.org/10.5194/bg-12-2311-2015.

21 I.U.S.S. Working Group WRB, 2006. World reference base for soil resources 2006. A 22 framework for international classification, correlation and communication. World Soil 23 Resources Reports No. 103. FAO, Rome, 128 pp. 
1 Kormann, R., Meixner, F.X., 2001. An analytical footprint model for non-neutral

2 stratification. Bound-Lay Meteorol 99 (2), 207-224.

3 http://dx.doi.org/10.1023/A:1018991015119.

4 Kristensen, A.H., Thorbjørn, A., Jensen, M.P., Pedersen, M., Moldrup, P., 2010. Gas-phase

5 diffusivity and tortuosity of structured soils. J Contam Hydrol 115 (1-4), 26-33.

6 http://dx.doi.org/10.1016/j.jconhyd.2010.03.003.

7 Kuzyakov, Y., 2006. Sources of $\mathrm{CO}_{2}$ efflux from soil and review of partitioning methods. Soil Biol Biochem 38 (3), 425-448. http://dx.doi.org/10.1016/j.soilbio.2005.08.020.

Kuzyakov, Y., Domanski, G., 2000. Carbon input by plants into the soil. Review. J Plant Nutr Soil Sci 163 (4), 421-431. http://dx.doi.org/0.1002/1522-2624(200008)163:4<421::aid-jpln421>3.0.co;2-r.

Leafe, E.L., Stiles, W., Dickinson, S.E., 1974. Physiological processes influencing the pattern of productivity of the intensively managed grass sward. Sectional Papers, 12th http://dx.doi.org/10.1111/jac.12032. 52 (280), 552-566. http://dx.doi.org/10.2307/2281706. 
1 Massman, W.J., Lee, X., 2002. Eddy covariance flux corrections and uncertainties in long-

2 term studies of carbon and energy exchanges. Agr Forest Meteorol 113 (1-4), 121-144.

3 http://dx.doi.org/10.1016/s0168-1923(02)00105-3.

4 Mauder, M., Cuntz, M., Drüe, C., Graf, A., Rebmann, C., Schmid, H.P., Schmidt, M.,

5 Steinbrecher, R., 2013. A strategy for quality and uncertainty assessment of long-term

6 eddy-covariance measurements. Agr Forest Meteorol 169, 122-135.

7 http://dx.doi.org/10.1016/j.agrformet.2012.09.006.

8 Moureaux, C., Debacq, A., Hoyaux, J., Suleau, M., Tourneur, D., Vancutsem, F., Bodson, B., Aubinet, M., 2008. Carbon balance assessment of a Belgian winter wheat crop (Triticum aestivum L.). Glob Change Biol 14 (6), 1353-1366. http://dx.doi.org/10.1111/j.1365-2486.2008.01560.x.

Moyano, F.E., Vasilyeva, N., Bouckaert, L., Cook, F., Craine, J., Curiel Yuste, J., Don, A., Epron, D., Formanek, P., Franzluebbers, A., Ilstedt, U., Kätterer, T., Orchard, V., Reichstein, M., Rey, A., Ruamps, L., Subke, J.-A., Thomson, I.K., Chenu, C., 2012. The moisture response of soil heterotrophic respiration: interaction with soil properties. Biogeosciences 9 (3), 1173-1182. http://dx.doi.org/10.5194/bg-9-1173-2012.

Nash, J.E., Sutcliffe, J.V., 1970. River flow forecasting through conceptual models. Part I - a discussion of principles. J Hydrol 10 (3), 282-290. http://dx.doi.org/10.1016/0022-1694(70)90255-6.

Nelder, J.A., Mead, R., 1965. A simplex method for function minimization. Comput J 7 (4), 308-313.

Palosuo, T., Foereid, B., Svensson, M., Shurpali, N., Lehtonen, A., Herbst, M., Linkosalo, T., Ortiz, C., Todorovic, G.R., Marcinkonis, S., Li, C., Jandl, R., 2012. A multi-model comparison of soil carbon assessment of a coniferous forest stand. Environ Modell Softw 35, 38-49. http://dx.doi.org/10.1016/j.envsoft.2012.02.004. 
1 Parsons, A.J., 1988. The effects of season and management on the growth of grass swards, in:

2 Jones, M.B., Lazenby, A. (Eds.), The grass crop. The physiological basis of production.

3 Chapman and Hall, London, New York, pp. 129-177.

4 Parsons, A.J., Robson, M.J., 1981. Seasonal changes in the physiology of S24 perennial

5 ryegrass (Lolium perenne L.). 3. Partition of assimilates between root and shoot during the 6 transition from vegetative to reproductive growth. Ann Bot 48 (5), 733-744.

7 Post, H., Hendricks Franssen, H.J., Graf, A., Schmidt, M., Vereecken, H., 2015. Uncertainty analysis of eddy covariance $\mathrm{CO}_{2}$ flux measurements for different $\mathrm{EC}$ tower distances using an extended two-tower approach. Biogeosciences 12 (4), 1205-1221. http://dx.doi.org/10.5194/bg-12-1205-2015.

Prolingheuer, N., Scharnagl, B., Graf, A., Vereecken, H., Herbst, M., 2014. On the spatial variation of soil rhizospheric and heterotrophic respiration in a winter wheat stand. Agr Forest Meteorol 195-196, 24-31. http://dx.doi.org/10.1016/j.agrformet.2014.04.016.

Prud'homme, M.-P., Gonzalez, B., Billard, J.-P., Boucaud, J., 1992. Carbohydrate content, fructan and sucrose enzyme activities in roots, stubble and leaves of ryegrass (Lolium perenne L.) as affected by source/sink modification after cutting. J Plant Physiol 140, 282-291.

Reichstein, M., Falge, E., Baldocchi, D., Papale, D., Aubinet, M., Berbigier, P., Bernhofer, C., Buchmann, N., Gilmanov, T., Granier, A., Grünwald, T., Havránková, K., Ilvesniemi, H., Janous, D., Knohl, A., Laurila, T., Lohila, A., Loustau, D., Matteucci, G., Meyers, T., Miglietta, F., Ourcival, J.-M., Pumpanen, J., Rambal, S., Rotenberg, E., Sanz, M., Tenhunen, J., Seufert, G., Vaccari, F., Vesala, T., Yakir, D., Valentini, R., 2005. On the separation of net ecosystem exchange into assimilation and ecosystem respiration: review and improved algorithm. Global Change Biology 11 (9), 1424-1439. http://dx.doi.org/10.1111/j.1365-2486.2005.001002.x. 
1 Richardson, A.D., Williams, M., Hollinger, D.Y., Moore, D.J.P., Dail, D.B., Davidson, E.A.,

2 Scott, N.A., Evans, R.S., Hughes, H., Lee, J.T., Rodrigues, C., Savage, K., 2010.

3 Estimating parameters of a forest ecosystem $\mathrm{C}$ model with measurements of stocks and

4 fluxes as joint constraints. Oecologia 164 (1), 25-40.

5 http://dx.doi.org/10.1007/s00442-010-1628-y.

6 Robson, M.J., Ryle, G.J.A., Woledge, J., 1988. The grass plant - its form and function, in:

7 Jones, M.B., Lazenby, A. (Eds.), The grass crop. The physiological basis of production.

8 Chapman and Hall, London, New York, pp. 25-83.

9 Rustad, L.E., Huntington, T.G., Boone, R.D., 2000. Controls on soil respiration: Implications

10 for climate change. Biogeochemistry 48 (1), 1-6.

11 http://dx.doi.org/10.1023/A:1006255431298.

12 Rutter, A.J., Kershaw, K.A., Robins, P.C., Morton, A.J., 1971. A predictive model of rainfall interception in forests, 1. Derivation of the model from observations in a plantation of Corsican pine. Agr Meteorol 9, 367-384. http://dx.doi.org/10.1016/0002-1571(71)90034-3. LINGRA, a sink/source model to simulate grassland productivity in Europe. Eur J Agron 9, 87-100. http://dx.doi.org/10.1016/S1161-0301(98)00027-6.

Scharnagl., B., Vrugt, J.A., Vereecken, H., Herbst, M., 2011. Inverse modelling of in situ soil water dynamics: investigating the effect of different prior distributions of the soil hydraulic parameters. Hydrol Earth Syst Sci 15 (10), 3043-3059. http://dx.doi.org/10.5194/hess-15-3043-2011.

Schmidt, M., Reichenau, T.G., Fiener, P., Schneider, K., 2012. The carbon budget of a winter wheat field: An eddy covariance analysis of seasonal and inter-annual variability. Agr Forest Meteorol 165, 114-126. http://dx.doi.org/10.1016/j.agrformet.2012.05.012. 
1 Schmitt, M., Bahn, M., Wohlfahrt, G., Tappeiner, U., Cernusca, A., 2010. Land use affects

2 the net ecosystem $\mathrm{CO}_{2}$ exchange and its components in mountain grasslands.

3 Biogeosciences 7 (8), 2297-2309. http://dx.doi.org/10.5194/bg-7-2297-2010.

4 Séquaris, J.-M., Klumpp, E., Vereecken, H., 2013. Colloidal properties and potential release of water-dispersible colloids in an agricultural soil depth profile. Geoderma 193, 94-101. http://dx.doi.org/10.1016/j.geoderma.2012.10.014.

Šimůnek, J., Suarez, D.L., 1993. Modeling of carbon dioxide transport and production in soil 1. Model development. Water Resour Res 29 (2), 487-497. http://dx.doi.org/10.1029/92WR02225.

Šimůnek, J., Suarez, D.L., Šejna, M., 1996. The UNSATCHEM Software Package for simulating the one-dimensional variably saturated water flow, heat transport, carbon dioxide production and transport, and multicomponent solute transport with major ion equilibrium and kinetic chemistry, Version 2.0. Research Report No. 141. U.S. Salinity Laboratory, Agricultural Research Service, U.S. Department of Agriculture, Riverside, California, 186 pp.

Skjemstad, J.O., Spouncer, L.R., Cowie, B., Swift, R.S., 2004. Calibration of the Rothamsted organic carbon turnover model (RothC ver. 26.3), using measurable soil organic carbon pools. Aust J Soil Res 42 (1), 79-88. http://dx.doi.org/10.1071/sr03013.

Skopp, J., Jawson, M.D., Doran, J.W., 1990. Steady-state aerobic microbial activity as a function of soil water content. Soil Sci Soc Am J 54 (6), 1619-1625.

Soussana, J.F., Allard, V., Pilegaard, K., Ambus, P., Amman, C., Campbell, C., Ceschia, E., Clifton-Brown, J., Czobel, S., Domingues, R., Flechard, C., Fuhrer, J., Hensen, A., Horvath, L., Jones, M., Kasper, G., Martin, C., Nagy, Z., Neftel, A., Raschi, A., Baronti, 
$1 \quad$ sites. Agr Ecosyst Environ 121 (1-2), 121-134.

2 http://dx.doi.org/10.1016/j.agee.2006.12.022.

3 Spitters, C.J.T., van Keulen, H., van Kraalingen., D.W.G., 1989. A simple and universal crop

4 growth simulator, SUCROS87, in: Rabbinge, R., Ward, S.A., van Laar, H.H., (Eds.),

5 Simulation and systems management in crop protection. Simulation Monographs 32,

$6 \quad$ PUDOC, Wageningen, pp. 147-181.

7 Stadler, A., Rudolph, S., Kupisch, M., Langensiepen, M., van der Kruk, J., Ewert, F., 2015.

8 Quantifying the effects of soil variability on crop growth using apparent soil electrical

9 conductivity measurements. Eur J Agron 64, 8-20.

10 http://dx.doi.org/10.1016/j.eja.2014.12.004.

11 Subke, J.-A., Inglima, I., Cotrufo, M.F., 2006. Trends and methodological impacts in soil $\mathrm{CO}_{2}$ 12 efflux partitioning: A metaanalytical review. Glob Change Biol 12 (6), 921-943. http://dx.doi.org/10.1111/j.1365-2486.2006.01117.x.

Suleau, M., Moureaux, C., Dufranne, D., Buysse, P., Bodson, B., Destain, J.-P., Heinesch, B., Debacq, A., Aubinet, M., 2011. Respiration of three Belgian crops: Partitioning of total ecosystem respiration in its heterotrophic, above- and below-ground autotrophic components. Agr Forest Meteorol 151 (5), 633-643. http://dx.doi.org/10.1016/j.agrformet.2011.01.012.

Supit, I., Hooijer, A.A., van Diepen, C.A., 1994. System description of the WOFOST 6.0 Crop Simulation Model implemented in CGMS. Volume 1: theory and algorithms. EUR 15956 EN, Joint Research Centre, European Commission, Luxembourg. 146 pp.

Sus, O., Williams, M., Bernhofer, C., Béziat, P., Buchmann, N., Ceschia, E., Doherty, R., Eugster, W., Grünwald, T., Kutsch, W., Smith, P., Wattenbach, M., 2010. A linked carbon cycle and crop developmental model: Description and evaluation against measurements of 
1 carbon fluxes and carbon stocks at several European agricultural sites. Agr Ecosyst

2 Environ 139 (3), 402-418. http://dx.doi.org/10.1016/j.agee.2010.06.012.

3 Swinnen, J., van Veen, J.A., Merckx, R., 1995. Carbon fluxes in the rhizosphere of winter

4 wheat and spring barley with conventional vs integrated farming. Soil Biol Biochem 27 (6), 811-820. http://dx.doi.org/10.1016/0038-0717(94)00230-X.

6 Trudinger, C.M., Raupach, M.R., Rayner, P.J., Kattge, J., Liu, Q., Pak, B., Reichstein, M., 7 Renzullo, L., Richardson, A.D., Roxburgh, S.H., Styles, J., Wang, Y.P., Briggs, P., Barrett, D., Nikolova, S., 2007. OptIC: An intercomparison of optimization techniques for parameter estimation in terrestrial biogeochemical models. J Geophys Res 112, G02027, 17 pp. http://dx.doi.org/10.1029/2006jg000367.

Twine, T.E., Kustas, W.P., Norman, J.M., Cook, D.R., Houser, P.R., Meyers, T.P., Prueger, J.H., Starks, P.J., Wesely, M.L., 2000. Correcting eddy-covariance flux underestimates over a grassland. Agr Forest Meteorol 103 (3), 279-300. http://dx.doi.org/10.1016/s0168-1923(00)00123-4. van Genuchten, M.T., 1980. A close-form equation for predicting the hydraulic conductivity of unsaturated soils. Soil Sci Soc Am J 44 (5), 892-898.

van Keulen, H., Goudriaan, J., Stroosnijder, L., Lantinga, E.A., van Laar, H.H., 1997. Crop growth model for water-limited conditions (SUCROS2), in: van Laar, H.H., Goudriaan, J., van Keulen, H. (Eds.), SUCROS97: Simulation of crop growth for potential and waterlimited production situations. As applied to spring wheat. Quantitative Approaches in Systems Analysis, AB-DLO, Wageningen, pp. 21-58.

Vanclooster, M., Viaene, P., Diels, J., Christiaens, K., 1995. WAVE: A mathematical model for simulating water and agrochemicals in the soil and vadose environment: Reference and user's manual (release 2.0). Institute for Land and Water Management, Katholieke Universiteit, Leuven, Belgium. 154 pp. 
1 Wang, W., Fang, J., 2009. Soil respiration and human effects on global grasslands. Global

2 Planet Change 67 (1-2), 20-28. http://dx.doi.org/10.1016/j.gloplacha.2008.12.011.

3 Wang, Y.-P., Trudinger, C.M., Enting, I.G., 2009. A review of applications of model-data fusion to studies of terrestrial carbon fluxes at different scales. Agr Forest Meteorol 149 (11), 1829-1842. http://dx.doi.org/10.1016/j.agrformet.2009.07.009.

Wattenbach, M., Sus, O., Vuichard, N., Lehuger, S., Gottschalk, P., Li, L., Leip, A., Williams, M., Tomelleri, E., Kutsch, W.L., Buchmann, N., Eugster, W., Dietiker, D., Aubinet, M., Ceschia, E., Béziat, P., Grünwald, T., Hastings, A., Osborne, B., Ciais, P., Cellier, P., Smith, P., 2010. The carbon balance of European croplands: A cross-site comparison of simulation models. Agr Ecosyst Environ 139 (3), 419-453. http://dx.doi.org/10.1016/j.agee.2010.08.004.

Webster, R., 1997. Regression and functional relations. Eur J Soil Sci 48 (3), 557-566. http://dx.doi.org/10.1046/j.1365-2389.1997.00099.x.

Weihermüller, L., Huisman, J.A., Graf, A., Herbst, M., Séquaris, J.-M., 2009. Multistep outflow experiments to determine soil physical and carbon dioxide production parameters. Vadose Zone J 8 (3), 772-782. http://dx.doi.org/10.2136/vzj2008.0041.

Weihermüller, L., Graf, A., Herbst, M., Vereecken, H., 2013. Simple pedotransfer functions to initialize reactive carbon pools of the RothC model. Eur J Soil Sci 64 (5), 567-575. http://dx.doi.org/10.1111/ejss.12036.

Williams, M., Richardson, A.D., Reichstein, M., Stoy, P.C., Peylin, P., Verbeeck, H., Carvalhais, N., Jung, M., Hollinger, D.Y., Kattge, J., Leuning, R., Luo, Y., Tomelleri, E., Trudinger, C.M., Wang, Y.-P., 2009. Improving land surface models with FLUXNET data. Biogeosciences 6 (7), 1341-1359.

Wohlfahrt, G., Hammerle, A., Haslwanter, A., Bahn, M., Tappeiner, U., Cernusca, A., 2008. 
1 mountain grassland: Effects of weather and management. J Geophys Res 113, D08110,

214 pp. http://dx.doi.org/10.1029/2007JD009286.

3 Wu, X., Luo, Y., Weng, E., White, L., Ma, Y., Zhou, X., 2009. Conditional inversion to

4 estimate parameters from eddy-flux observations. J Plant Ecol 2 (2), 55-68.

$5 \quad$ http://dx.doi.org/10.1093/jpe/rtp005.

6 Yuan, W., Liang, S., Liu, S., Weng, E., Luo, Y., Hollinger, D., Zhang, H., 2012. Improving

7 model parameter estimation using coupling relationships between vegetation production

8 and ecosystem respiration. Ecol Model 240, 219-240.

9 http://dx.doi.org/10.1016/j.ecolmodel.2012.04.027.

10 Zacharias, S., Bogena, H., Samaniego, L., Mauder, M., Fuß, R., Pütz, T., Frenzel, M.,

11 Schwank, M., Baessler, C., Butterbach-Bahl, K., Bens, O., Borg, E., Brauer, A., Dietrich,

12 P., Hajnsek, I., Helle, G., Kiese, R., Kunstmann, H., Klotz, S., Munch, J.C., Papen, H.,

13 Priesack, E., Schmid, H.P., Steinbrecher, R., Rosenbaum, U., Teutsch, G., Vereecken, H.,

14 2011. A network of Terrestrial Environmental Observatories in Germany. Vadose Zone J

15 (3), 955-973. http://dx.doi.org/10.2136/vzj2010.0139.

16 Zimmermann, M., Leifeld, J., Schmidt, M.W.I., Smith, P., Fuhrer, J., 2007. Measured soil

17 organic matter fractions can be related to pools in the RothC model. Eur J Soil Sci 58 (3),

18 658-667. http://dx.doi.org/10.1111/j.1365-2389.2006.00855.x. 


\section{APPENDIX}

\section{Appendix A: The AgroC Model}

Hourly Time Step

The SOILCO2/RothC model has a flexible time stepping scheme, however the original

6 SUCROS model explicitly runs at a daily time step. Since NEE typically shows distinct diurnal variations, the SUCROS code was adapted to work with an hourly time step. Only the calculation of development stage DVS (-) still relies on the original approach based on the effective temperature sum. In the SUCROS model, daily total gross assimilation is obtained by three-point Gauss integration of the instantaneous assimilation rates per unit leaf area over the daylight period. This integration was omitted in the AgroC model with an hourly time step. Hourly gross assimilation is computed from the hourly average inputs of global radiation and mean temperature using the same approach that was used for the instantaneous assimilation rate in the original code. Major changes were required for the estimation of the photosynthetic active radiation (PAR) flux at the top of the canopy. In SUCROS, instantaneous PAR $\left(\mathrm{J}[\mathrm{L}]^{-2}[\mathrm{~T}]^{-1}\right)$ is estimated from the sine of solar inclination $\sin B(-)$ and the daily integral of $\sin B$ including a correction of lower atmospheric transmittance at lower solar elevation $\operatorname{din} B E\left(\mathrm{~s} \mathrm{~d}^{-1}\right)$. The integral daily value $d \sin B E$ is approximated and $\sin B$ is estimated for the day of the year in dependence of the geographic position. In AgroC, the hourly integral of the sine of solar inclination $\operatorname{dsin} B\left(\mathrm{~s} \mathrm{~h}^{-1}\right)$ is now calculated using the

21 trapezoidal rule according to: 
1 where instantaneous $\sin B_{t-1}(=\sin (\delta) \sin (\varphi)+\cos (\delta) \cos (\omega) \cos (\varphi))$ is the sine of solar

2 elevation of the previous hour, $\delta\left(^{\circ}\right)$ is the sun declination angle, $\varphi\left(^{\circ}\right)$ is the geographic

3 latitude, $\omega\left({ }^{\circ}\right)$ is the hour angle, and $t_{s}(\mathrm{~s})$ is the number of seconds with astronomically

4 possible solar radiation within one hour (3600 during day, 0 during night, and a value in

5 between for the two hours that include sunrise and sunset). The value of $d \sin B E$ is then

6 estimated as:

7

$8 d \sin B E=\sin \left(\arcsin \left(0.5\left(\sin B_{t-1}+\sin B\right)\right)+0.4\left(0.5\left(\sin B_{t-1}+\sin B\right)\right)\right) t_{s}$ amount of interception $N_{i}\left(\left[\mathrm{~L} \mathrm{~T}^{-1}\right]\right)$ is then estimated according to:

where 0.4 is the regression coefficient between transmission and solar angle (Supit et al., 1994).

\section{Water Fluxes}

The coupling between SOILCO2 and SUCROS involves two hydrological processes: rainfall interception and root water uptake. Interception loss is estimated according to the single-bigleaf concept (Rutter et al., 1971). The canopy interception storage capacity $S_{i}$ ([L]) was assumed to be proportional to the total leaf area index $L A I\left(\left[\mathrm{~L}^{2} \mathrm{~L}^{-2}\right]\right)$. Water is removed from the interception storage by evaporation $E_{i}\left(\left[\mathrm{~L} \mathrm{~T}^{-1}\right]\right)$ :

$$
E_{i}=\left(E T_{p, c r o p}-E_{p}\right) \frac{C_{i}}{S_{i}}
$$


$1 \quad N_{i}=\left\{\begin{array}{crl}0 & & N_{0}=0 \\ S_{i}-C_{i} & \text { for } & S_{i}-C_{i}<N_{0} \\ N_{0} & & S_{i}-C_{i}>N_{0}\end{array}\right.$

3 where $N_{0}\left(\left[\mathrm{~L} \mathrm{~T}^{-1}\right]\right)$ represents precipitation. The amount of precipitation entering the soil $N_{p}$

$4\left(\left[\mathrm{~L} \mathrm{~T}^{-1}\right]\right)$ is calculated as the difference between $N_{0}$ and $N_{i}$.

5 In SUCROS, $E T_{p, c r o p}$ is computed by scaling the potential grass reference evapotranspiration

6 (Penman-Monteith approach; Allen et al., 1998) with the dimensionless crop conversion

7 factor $K_{c}$. On the basis of Beer's law, $E T_{p, c r o p}$ is split into potential soil evaporation $E_{p}$

$8 \quad\left(\left[\mathrm{~L} \mathrm{~T}^{-1}\right]\right)$ and potential transpiration $T_{p}\left(\left[\mathrm{~L} \mathrm{~T}^{-1}\right]\right)$ in dependence of $L A I$ :

9

$10 E_{p}=E T_{p, \text { crop }} \exp (-0.6 \cdot L A I)$

$11 T_{p}=E T_{p, \text { crop }}-E_{p}-E_{i}$

13 The potential soil evaporation is passed to SOILCO2, where it is used to prescribe the potential upward water flux as upper boundary condition. Potential transpiration is distributed over soil depth according to the relative root density distribution to provide the potential sink term for root water uptake. The depth-specific actual root water uptake is computed by scaling

17 the potential root water uptake with reduction factor $\alpha(-)$ in dependence of soil pressure head $h$ ([L]) following the approach of Feddes et al. (1978):

$20 \quad \alpha(h)=\left\{\begin{array}{crl}\frac{h_{0}-h}{h_{0}-h_{1}} & & h_{0} \leq h \leq h_{1} \\ 1 & \text { for } \quad & h_{1} \leq h \leq h_{2} \\ 10^{\frac{h_{2}-h}{h_{3}}} & & h_{2} \leq h \leq h_{3}\end{array}\right.$

22 where $h_{0}, h_{1}, h_{2}$, and $h_{3}([\mathrm{~L}])$ are prescribed threshold pressure heads (Vanclooster et al., 1995), which are plant dependent (Tab. A.2). Integration of the actual root water uptake over 
1 depth provides the actual transpiration $T_{a}\left(\left[\mathrm{~L} \mathrm{~T}^{-1}\right]\right)$. The reduction of stomatal conductance

2 due to water stress was assumed to correspond to the ratio between actual and potential 3 transpiration $T_{a} / T_{p}$.

4

5

Carbon Fluxes

6 In this study, carbon fluxes from the atmosphere to the ecosystem (downward) are defined as

7 negative fluxes, and upward fluxes are defined as positive. The water stress ratio $\left(T_{a} / T_{p}\right)$ is 8 used to scale gross carbon assimilation and to account for the effect of limited soil water 9 availability on crop activity in terms of gross primary productivity $\operatorname{GPP}\left(\mathrm{mol} \mathrm{CO}_{2}[\mathrm{~L}]^{-2}[\mathrm{~T}]^{-1}\right)$ :

$11 \quad G P P=-\frac{G_{p h o t}}{M l_{\mathrm{CH}_{2} \mathrm{O}} \mathrm{O}} \cdot \frac{T_{a}}{T_{p}}$

13 where $G_{\text {phot }}\left(\mathrm{kg} \mathrm{CH}_{2} \mathrm{O}[\mathrm{L}]^{-2}[\mathrm{~T}]^{-1}\right)$ is the glucose equivalent of the total gross assimilation per 14 time step (Spitters et al., 1989), and $\mathrm{Mol}_{\mathrm{CH}_{2} \mathrm{O}}$ is the molar mass of $\mathrm{CH}_{2} \mathrm{O}\left(=0.030 \mathrm{~kg} \mathrm{~mol}^{-1}\right)$. 15 The net primary productivity $\operatorname{NPP}\left(\operatorname{mol~CO}_{2}[\mathrm{~L}]^{-2}[\mathrm{~T}]^{-1}\right)$ is defined as:

16

$N P P=G P P+R_{g r}+R_{m}$

18

19 where $R_{g r}\left(\operatorname{mol~CO} \mathrm{CL}^{-2}[\mathrm{~T}]^{-1}\right)$ is the total growth respiration, and $R_{m}\left(\mathrm{~mol} \mathrm{CO}_{2}[\mathrm{~L}]^{-2}[\mathrm{~T}]^{-1}\right)$ is 20 the maintenance respiration. Net ecosystem exchange $N E E\left(\operatorname{mol~CO}{ }_{2}[\mathrm{~L}]^{-2}[\mathrm{~T}]^{-1}\right)$ is computed 21 as: 
1 where $R_{h}\left(\mathrm{~mol} \mathrm{CO} 2[\mathrm{~L}]^{-2}[\mathrm{~T}]^{-1}\right)$ is the depth-integral of the heterotrophic $\mathrm{CO}_{2}$ source term

2 provided by the RothC module.

3

4

6

7

8

9

10

11

12

$R_{m, r}=\sum_{o=1}^{4} f_{m, o} W_{o} f_{t}$

where $f_{m, o}\left(\mathrm{~kg} \mathrm{CH}_{2} \mathrm{O} \mathrm{kg}{ }^{-1} \mathrm{DM}[\mathrm{T}]^{-1}\right)$ is the maintenance coefficient with index $o$ looping over the four plant organs leaves, stems, roots, and storage organs with coefficients of $0.03,0.015$, 0.015 , and 0.01 , respectively (Spitters et al., 1989), $W_{o}\left(\mathrm{~kg} \mathrm{DM}[\mathrm{L}]^{-2}\right)$ is the respective organ dry weight, and $f_{t}(-)$ is a time conversion factor accounting for the use of an hourly or daily time step. In a second step, $R_{m, r}$ is corrected for temperature to estimate total maintenance respiration $R_{m, c}\left(\mathrm{~kg} \mathrm{CH}_{2} \mathrm{O}[\mathrm{L}]^{-2}[\mathrm{~T}]^{-1}\right)$ as described by Spitters et al. (1989) and converted to $\mathrm{CO}_{2}$ equivalent maintenance respiration $R_{m}\left(\operatorname{mol~CO} 2[\mathrm{~L}]^{-2}[\mathrm{~T}]^{-1}\right)$ by dividing with $\mathrm{Mol}_{\mathrm{CH}_{2} O}$. Total growth respiration $R_{\text {gtot }}\left(\mathrm{kg} \mathrm{CH}_{2} \mathrm{O}[\mathrm{L}]^{-2}[\mathrm{~T}]^{-1}\right)$ in glucose equivalents is estimated as:

$$
R_{\text {gtot }}=\left(G_{\text {phot }} \cdot \frac{T_{a}}{T_{p}}-R_{m, c}\right)-\Delta W \cdot C_{\text {cont }} \cdot \frac{M_{o l} \mathrm{CH}_{2} \mathrm{O}}{\mathrm{Mol}_{C}}
$$

where $\Delta W\left(\mathrm{~kg} \mathrm{DM}[\mathrm{L}]^{-2}[\mathrm{~T}]^{-1}\right)$ is the overall dry matter growth rate, $C_{\text {cont }}\left(\mathrm{g} \mathrm{C} \mathrm{g}^{-1} \mathrm{DM}\right)$ is the conversion factor between carbon and biomass dry matter weight, and $\mathrm{Mol}_{C}$ is the molar mass of C $\left(=0.012 \mathrm{~kg} \mathrm{~mol}^{-1}\right)$. Growth respiration for each plant organ $R_{g r, o}\left(\mathrm{~mol} \mathrm{CO}_{2}[\mathrm{~L}]^{-2}[\mathrm{~T}]^{-1}\right)$ is computed from $R_{\text {gtot }}$ according to: 
$1 \quad R_{g r, o}=\frac{R g t o t}{M l_{C H} \mathrm{O}}$

2

3 where index $o$ loops over the four plant organs, and $f_{o}(-)$ is the organ-specific partitioning

4 factor. Total growth respiration $R_{g r}\left(\mathrm{~mol} \mathrm{CO}_{2}[\mathrm{~L}]^{-2}[\mathrm{~T}]^{-1}\right)$ is finally computed as the sum of all 5 $R_{g r, o}$. The sum of maintenance and growth respiration of the roots represents the autotrophic source term of soil $\mathrm{CO}_{2}$ and is distributed over the soil profile according to the time-variable relative root density distribution.

\section{Root Exudation and Root Decay}

In SUCROS, the daily or hourly glucose assimilation rate $G_{p h o t}\left(\mathrm{~kg} \mathrm{CH}_{2} \mathrm{O}[\mathrm{L}]^{-2}[\mathrm{~T}]^{-1}\right)$ is partitioned in dependence of the DVS into the fraction for the shoot and for the root system to build up biomass. According to labelling experiments performed by Swinnen et al. (1995) for winter wheat, $18.2 \%$ of net assimilation is transferred to the roots, $7.1 \%$ are used to build up root biomass, and 5.3\% are released as young photosynthetate rhizodeposition. This translates into fractions of 0.39 and 0.29 for root biomass build-up and exudates, respectively, relative to net assimilation transferred to the roots. The remaining fraction consists of root respiration and root decay. The relative root exudation factor $f_{\text {exu }}(-)$ thus equals 0.43 $(=0.29 /(0.39+0.29))$. In AgroC, the root exudation rate $R t_{\text {exu }}\left(\mathrm{kg} \mathrm{C}[\mathrm{L}]^{-2}[\mathrm{~T}]^{-1}\right)$ is computed according to this partitioning factor from the dry matter root growth rate $\Delta W_{r t}$ $\left(\operatorname{kg~DM}[\mathrm{L}]^{-2}[\mathrm{~T}]^{-1}\right)$ :

$$
R t_{\text {exu }}=\Delta W_{r t} \cdot f_{r t} \cdot f_{\text {exu }} \cdot 0.467
$$


1 simulated root exudation shows diurnal variations due to the dependence on the assimilation

2 rate, as suggested by Hopkins et al. (2013) and Kuzyakov (2006) amongst others.

3 Swinnen et al. (1995) reported that $3.1 \%$ of the net assimilation ends up as dead roots. In

4 relation to the $18.2 \%$ transferred to the roots, this equals a relative fraction of 0.17 . In order to

5 account for this, a root death factor $f_{\text {dea }}(-)$ was introduced. It was assumed that $f_{\text {dea }}$ is lower

6 during the crop juvenile stages than at flowering:

7

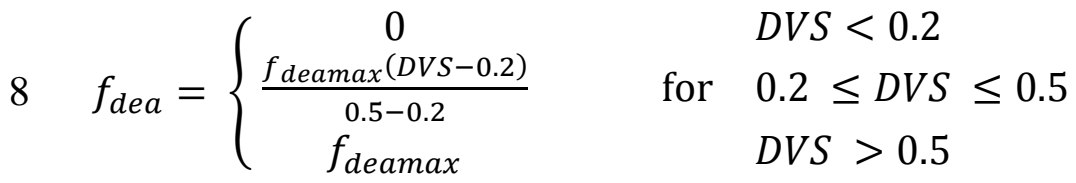

10 where $f_{\text {dea }}$ is the root death factor in relation to the total amount of roots, and $f_{\text {deamax }}(-)$ is the 11 maximum value of the root death factor. For winter wheat, a $f_{\text {deamax }}$ of 0.43 was used, which approximately reproduced the cumulative fraction of dead roots of 0.17 of net assimilation determined by Swinnen et al. (1995). The rate of root death in terms of carbon release $R t_{d e a}$

$14 \quad\left(\mathrm{~kg} \mathrm{C}[\mathrm{L}]^{-2}[\mathrm{~T}]^{-1}\right)$ is computed as:

15

$16 R t_{\text {dea }}=\Delta W_{r t} \cdot f_{r t} \cdot f_{\text {dea }} \cdot 0.467$

$\Delta W_{r t}$ is reduced according to the loss of root exudates and dead roots. The total amount of root exudates and dead roots is again distributed over depth according to the relative root density profile. The carbon equivalent of the root exudates is transferred to the depth-specific decomposable plant material pool (DPM) of the RothC subroutine because of the expected rapid decomposition of these labile substances by rhizosphere microorganisms. The carbon equivalent of the dead roots is split into the DPM and the resistant plant material (RPM) pool 
1 according to the original RothC partitioning factor for incoming plant material of 0.59 and

20.41 (Coleman and Jenkinson, 2008), respectively.

3 For winter wheat and barley, harvest residues are also considered. At the time of harvest, root

4 biomass and $25 \%$ of stem biomass is added to the DPM and RPM pool up to a user-specified 5 soil depth (i.e. ploughing depth). Figure 1 provides a summary of the carbon cycling in 6 AgroC.

Grassland

9 The original SUCROS code is not capable of simulating managed grassland, which are characterized by multiple mowing events over the season. Mowing is associated with the transfer of glucose from roots and stubble to the leaves, which allows for a faster compensation of defoliation. The routines implemented in AgroC for the simulation of the above-mentioned processes follow the sink/source approach suggested by Schapendonk et al. (1998) for the grassland productivity model LINGRA.

At prescribed mowing dates, the current green leaf area index $L A I_{g}$ is set to a fixed postmowing leaf area index $L A I_{\text {post }}$ (in this study we set $L A I_{\text {post }}=0.35$ based on LAI measurements). The ratio between pre-mowing LAI and post-mowing $L A I_{\text {post }}$ is used to compute the respective loss of dry matter biomass:

$20 f_{l a i}=\frac{L A I_{g}}{L A I_{\text {post }}}$

$21 w_{\text {post }, i}=\frac{w_{\text {pre }, i}}{f_{\text {lai }}}$

23 where $f_{\text {lai }}(-)$ is the pre-/post-mowing LAI ratio, $w_{\text {pre }}\left(\mathrm{kg} \mathrm{DM}[\mathrm{L}]^{-2}\right)$ is the biomass prior to 24 mowing, and $w_{\text {post }}\left(\mathrm{kg} \mathrm{DM}[\mathrm{L}]^{-2}\right)$ is the respective biomass after mowing. The index $i$ loops over leaves, stems, and storage organs/inflorescence. At each mowing event, DVS is also 
1 reset to a prescribed value of $D V S_{\text {reset }}=0.5$. In order to simulate the transfer of glucose after

2 defoliation, we implemented a glucose storage that is filled between a $D V S_{l o}$ of 0.6 and a

$3 D V S_{h i}$ of 1.0. The rate of glucose storage increase $\lambda_{s+}\left(\mathrm{kg} \mathrm{CH}_{2} \mathrm{O}[\mathrm{L}]^{-2}[\mathrm{~T}]^{-1}\right)$ is computed as a

4 fraction $f_{\text {stor }}(-)$ of global net glucose production:

5

$6 \quad \lambda_{s+}=\left(G_{p h o t} \cdot \frac{T_{a}}{T_{p}}-R_{m, c}\right) \cdot f_{\text {stor }}$

7

8

9

11

12

$f_{\text {stor }}=\left\{\begin{array}{c}0 \\ \frac{f_{\text {stormax }}\left(D V S-D V S_{l o}\right)}{\left(D V S_{h i}-D V S_{l o}\right)} \\ f_{\text {stormax }}\end{array}\right.$
13

14 where $f_{\text {stormax }}(-)$ is the user-specified maximum storage fraction. Thus, the glucose storage 15

$$
\lambda_{s-}=\frac{\log (100)}{t_{s t o r}}
$$

where $t_{\text {stor }}([\mathrm{T}])$ is a user-specified time required to reach a value of $1 \%$ of the storage at the time of mowing. According to Gonzales et al. (1989) and Prud'homme et al. (1992), the $S_{\text {stor, },}\left(\mathrm{kg} \mathrm{CH}_{2} \mathrm{O}\left[\mathrm{L}^{-2}\right)\right.$ increases by $\lambda_{s+}$ until a user-defined maximum value of $S_{\text {stormax }}$ $\left(\mathrm{kg} \mathrm{CH}_{2} \mathrm{O}[\mathrm{L}]^{-2}\right)$ is reached. After that, $S_{\text {stor, }}$ remains constant. After mowing, the dry matter transfer rate $\lambda_{s^{-}}\left(\left[\mathrm{T}^{-1}\right]\right)$ from $S_{\text {stor, }}$ to the shoot is estimated as:

$$
\text { mobilization of carbohydrates in ryegrass is highest during the first } 6 \text { days after defoliation }
$$


1 and levels out in a second phase that lasts until 29 days after defoliation. In this study, $t_{\text {stor }}$ was

2 set to 15 days, which results in a $\lambda_{s-}$ of $0.31 \mathrm{~d}^{-1}$. Correspondingly, $S_{\text {stor, }}$ is reduced down to a

3 limiting value of zero according to:

4

$5 \quad S_{\text {stor }, t+1}=S_{\text {stor }, t}\left(1-\lambda_{s-}\right)$

6

7 The additional dry matter growth rate $\Delta W_{\text {stor }}\left(\mathrm{kg} \mathrm{DM}[\mathrm{L}]^{-2}[\mathrm{~T}]^{-1}\right)$ resulting from the declining $8 S_{\text {stor, } t}$ is added to the dry matter growth rate of the shoot $\Delta W_{s h,}\left(\operatorname{kg~DM}[\mathrm{L}]^{-2}[\mathrm{~T}]^{-1}\right)$, which is the

9 outcome of the photosynthetic activity of the plant. The additional shoot growth rate $\Delta W_{\text {stor }}$ is 10 computed as:

$\Delta W_{\text {stor }}=\frac{s_{s t o r, t} \lambda_{s-}}{f_{s h}\left(1.46 f_{l v}+1.51 f_{s t}\right)}$

13

14

where $f_{s h}, f_{l v}$, and $f_{s t}$ are the dimensionless partitioning factors for shoot, leaves, and stems, respectively. The assimilate requirement coefficients of 1.46 and 1.51 in Equation A.23 have a unit of $\mathrm{kg} \mathrm{CH}_{2} \mathrm{O} \mathrm{kg}^{-1} \mathrm{DM}$ (Spitters et al., 1989).

As suggested by Schapendonk et al. (1998), a mechanism was implemented by which the specific leaf area (ha leaf $\mathrm{kg}^{-1} \mathrm{DM}$ ) varies over the season as a function of DVS. Furthermore, a mechanism to distinguish between vegetative and reproductive development of grass was introduced as suggested by Barrett et al. (2004). These two stages of development differ in the productivity of grass and in several major physiological processes that alter the response of the plant to environmental drivers (e.g., Anslow and Green, 1967; Leafe et al., 1974; Parsons, 1988; Robson et al., 1988). 
1 Tab. A.1:

2 Site-specific soil properties $\left(\mathrm{C}_{\mathrm{org}}\right.$ : organic carbon content) and calibrated hydraulic parameters

$3 \quad\left(\theta_{\mathrm{r}}\right.$ : residual water content; $\theta_{\mathrm{s}}$ : saturated water content; $\alpha$ : inverse of the bubbling pressure; $n$ :

4 shape parameter; $K_{s}$ : saturated hydraulic conductivity; van Genuchten, 1980).

5

\begin{tabular}{|c|c|c|c|c|c|c|c|c|c|c|}
\hline & $\begin{array}{r}\text { soil profile } \\
\text { horizons }\end{array}$ & $\begin{array}{r}\text { sand } \\
(\%)\end{array}$ & $\begin{array}{l}\text { silt } \\
(\%)\end{array}$ & $\begin{array}{l}\text { clay } \\
(\%)\end{array}$ & $\begin{array}{l}\mathrm{C}_{\text {org }} \\
(\%)\end{array}$ & $\left(\mathrm{cm}^{3} \mathrm{~cm}^{-3}\right)^{\theta_{\mathrm{r}}}\left(\mathrm{cm}^{3}\right.$ & $\left.{ }^{3} \mathrm{~cm}^{-3}\right)^{\theta_{\mathrm{s}}}$ & $\begin{array}{r}\boldsymbol{\alpha} \\
\left(\mathbf{c m}^{-1}\right)\end{array}$ & $\begin{array}{r}n \\
(-)\end{array}$ & $\underset{\left(\mathrm{cm} \mathrm{h}^{-1}\right)}{\mathbf{K}_{\mathrm{s}}}$ \\
\hline \multirow{4}{*}{ 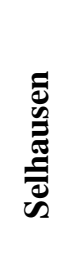 } & $0-15 \mathrm{~cm}$ & 15.4 & 67.5 & 17.1 & 1.03 & 0.069 & 0.504 & 0.0056 & 1.68 & 0.01 \\
\hline & $15-33 \mathrm{~cm}$ & 15.6 & 67.7 & 16.6 & 0.96 & 0.109 & 0.504 & 0.0059 & 1.92 & 0.05 \\
\hline & $33-57 \mathrm{~cm}$ & 16.2 & 63.1 & 23.1 & 0.34 & 0.000 & 0.463 & 0.0061 & 1.28 & 0.35 \\
\hline & $57-120 \mathrm{~cm}$ & 12.3 & 64.0 & 23.7 & 0.24 & 0.044 & 0.441 & 0.0013 & 1.69 & 0.05 \\
\hline \multirow{4}{*}{ 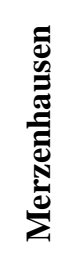 } & $0-12 \mathrm{~cm}$ & 6.4 & 78.2 & 15.4 & 1.0 & 0.001 & 0.462 & 0.0031 & 1.69 & 0.30 \\
\hline & $12-40 \mathrm{~cm}$ & 6.4 & 78.2 & 15.4 & 1.0 & 0.001 & 0.571 & 0.0039 & 1.63 & 0.41 \\
\hline & $40-60 \mathrm{~cm}$ & 1.0 & 77.1 & 21.9 & 0.4 & 0.057 & 0.418 & 0.0034 & 1.21 & 0.64 \\
\hline & $60-110 \mathrm{~cm}$ & 0.5 & 73.4 & 26.1 & 0.3 & 0.103 & 0.367 & 0.0017 & 1.88 & 0.13 \\
\hline \multirow{5}{*}{ 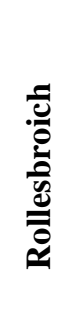 } & $0-5 \mathrm{~cm}$ & 22.0 & 60.8 & 17.2 & 4.82 & 0.034 & 0.443 & 0.0082 & 2.83 & 2.16 \\
\hline & $5-14 \mathrm{~cm}$ & 22.0 & 60.8 & 17.2 & 4.82 & 0.056 & 0.380 & 0.0077 & 2.84 & 2.04 \\
\hline & $14-34 \mathrm{~cm}$ & 23.1 & 59.1 & 17.8 & 2.49 & 0.039 & 0.379 & 0.0109 & 1.68 & 1.75 \\
\hline & $34-60 \mathrm{~cm}$ & 23.2 & 59.3 & 17.5 & 0.81 & 0.038 & 0.340 & 0.0160 & 1.33 & 0.84 \\
\hline & $60-100 \mathrm{~cm}$ & 23.2 & 59.3 & 17.5 & 0.0 & 0.037 & 0.375 & 0.0131 & 1.06 & 0.71 \\
\hline
\end{tabular}


1 Tab. A.2:

2 Selection of most important fitted plant parameters for the calibration of the plant growth

3 module of AgroC. (WW: winter wheat; WB: winter barley; GL: grassland; DVS:

4 development stage; DM: dry matter).

5

\begin{tabular}{|c|c|c|c|c|c|c|c|c|c|c|}
\hline & \multirow{2}{*}{\multicolumn{2}{|c|}{$\begin{array}{l}\text { Selhausen } \\
\text { WW } 2009\end{array}$}} & \multicolumn{6}{|c|}{ Merzenhausen } & \multirow{2}{*}{\multicolumn{2}{|c|}{$\begin{array}{l}\text { Rollesbroich } \\
\text { GL } 2013\end{array}$}} \\
\hline & & & \multicolumn{2}{|c|}{ WW 2012} & \multicolumn{2}{|c|}{ WW 2013} & \multicolumn{2}{|c|}{ WB 2014} & & \\
\hline $\begin{array}{l}\text { prescribed threshold pressure } \\
\text { heads } h_{0}, h_{1}, h_{2} \text {, and } h_{3} \text { for scaling } \\
\text { the root water uptake }(\mathrm{cm})\end{array}$ & \multicolumn{2}{|c|}{$\begin{array}{l}-10 \\
-100 \\
-300 \\
-800\end{array}$} & \multicolumn{2}{|c|}{$\begin{array}{l}-100, \\
-400, \\
-1000, \\
-10000\end{array}$} & \multicolumn{2}{|c|}{$\begin{array}{l}-100, \\
-400, \\
-1000, \\
-10000\end{array}$} & \multicolumn{2}{|c|}{$\begin{array}{l}-100, \\
-400, \\
-1000, \\
-10000\end{array}$} & \multicolumn{2}{|c|}{$\begin{array}{l}-5, \\
-70, \\
-150, \\
-800\end{array}$} \\
\hline $\begin{array}{l}\text { specific leaf area of new leaves } \\
\text { (ha leaf } \mathrm{kg}^{-1} \mathrm{DM} \text { ) }\end{array}$ & \multicolumn{2}{|c|}{0.0024} & \multicolumn{2}{|c|}{0.0024} & \multicolumn{2}{|c|}{0.0023} & \multicolumn{2}{|c|}{0.0033} & \multicolumn{2}{|c|}{0.003} \\
\hline $\begin{array}{l}\text { potential } \mathrm{CO}_{2} \text { assimilation rate of a } \\
\text { unit leaf area for light saturation } \\
\left(\mathrm{kg} \mathrm{CO}_{2} \mathrm{ha}^{-1} \text { leaf } \mathrm{h}^{-1}\right)\end{array}$ & \multicolumn{2}{|l|}{47.0} & \multicolumn{2}{|l|}{60.0} & \multicolumn{2}{|c|}{53.0} & \multicolumn{2}{|l|}{48.0} & \multicolumn{2}{|c|}{75.0} \\
\hline $\begin{array}{l}\text { initial light use efficiency } \\
\left(\left(\mathrm{kg} \mathrm{CO}_{2} \mathrm{ha}^{-1} \text { leaf } \mathrm{h}^{-1}\right)\left(\mathrm{J} \mathrm{m}^{-2} \mathrm{~s}^{-1}\right)^{-1}\right)\end{array}$ & \multicolumn{2}{|l|}{0.5} & \multicolumn{2}{|l|}{0.5} & \multicolumn{2}{|l|}{0.5} & \multicolumn{2}{|l|}{0.45} & \multicolumn{2}{|c|}{0.36} \\
\hline \multirow{6}{*}{$\begin{array}{l}\text { DVS against reduction factor of } \\
\text { the maximal light assimilation rate }\end{array}$} & 0.0 & 1.0 & 0.0 & 1.0 & 0.0 & 1.0 & 0.0 & 1.0 & 0.0 & 1.0 \\
\hline & 1.0 & 1.0 & 1.0 & 1.0 & 1.0 & 1.0 & 1.0 & 1.0 & 0.4 & 1.0 \\
\hline & 2.0 & 0.4 & 2.0 & 0.5 & 2.0 & 0.4 & 2.0 & 0.3 & 1.0 & 0.9 \\
\hline & & & & & & & & & 1.2 & 0.9 \\
\hline & & & & & & & & & 1.5 & 0.9 \\
\hline & & & & & & & & & 1.8 & 0.9 \\
\hline \multirow{6}{*}{$\begin{array}{l}\text { daily average daytime temperature } \\
\text { against reduction factor of the } \\
\text { maximal light assimilation rate }\end{array}$} & 0.0 & 0.05 & 0.0 & 0.01 & 0.0 & 0.05 & 0.0 & 0.6 & 0.0 & 0.4 \\
\hline & 4.0 & 0.3 & 6.0 & 0.3 & 6.0 & 0.1 & 5.0 & 0.7 & 5.0 & 0.6 \\
\hline & 10.0 & 0.6 & 10.0 & 0.7 & 10.0 & 0.5 & 15.0 & 0.9 & 10.0 & 1.0 \\
\hline & 15.0 & 0.8 & 17.0 & 1.0 & 20.0 & 1.0 & 18.0 & 1.0 & 15.0 & 1.0 \\
\hline & 20.0 & 1.0 & 25.0 & 0.5 & 25.0 & 0.7 & 25.0 & 0.6 & 20.0 & 0.8 \\
\hline & 30.0 & 0.0 & 35.0 & 0.4 & 35.0 & 0.6 & 40.0 & 0.3 & 35.0 & 0.2 \\
\hline \multirow{9}{*}{$\begin{array}{l}\text { DVS against fraction of dry matter } \\
\text { allocated to the shoot }\end{array}$} & 0.0 & 0.33 & 0.0 & 0.24 & 0.0 & 0.24 & 0.0 & 0.34 & 0.0 & 0.62 \\
\hline & 0.1 & 0.33 & 0.1 & 0.24 & 0.1 & 0.24 & 0.51 & 0.44 & 0.2 & 0.52 \\
\hline & 0.2 & 0.42 & 0.2 & 0.33 & 0.2 & 0.33 & 0.72 & 0.84 & 0.4 & 0.49 \\
\hline & 0.4 & 0.67 & 0.4 & 0.58 & 0.4 & 0.58 & 1.7 & 0.99 & 0.7 & 0.57 \\
\hline & 0.5 & 0.78 & 0.5 & 0.64 & 0.5 & 0.64 & 2.0 & 1.00 & 1.0 & 0.64 \\
\hline & 0.7 & 0.85 & 0.7 & 0.72 & 0.7 & 0.72 & & & 1.3 & 0.47 \\
\hline & 0.9 & 0.92 & 0.9 & 0.80 & 0.9 & 0.80 & & & 2.0 & 0.55 \\
\hline & 1.2 & 1.0 & 1.5 & 0.91 & 1.5 & 0.91 & & & & \\
\hline & 2.0 & 1.0 & 2.0 & 1.0 & 2.0 & 1.0 & & & & \\
\hline
\end{tabular}


1 Appendix B: Results and Discussions Supporting Figures

2 
considering NEE
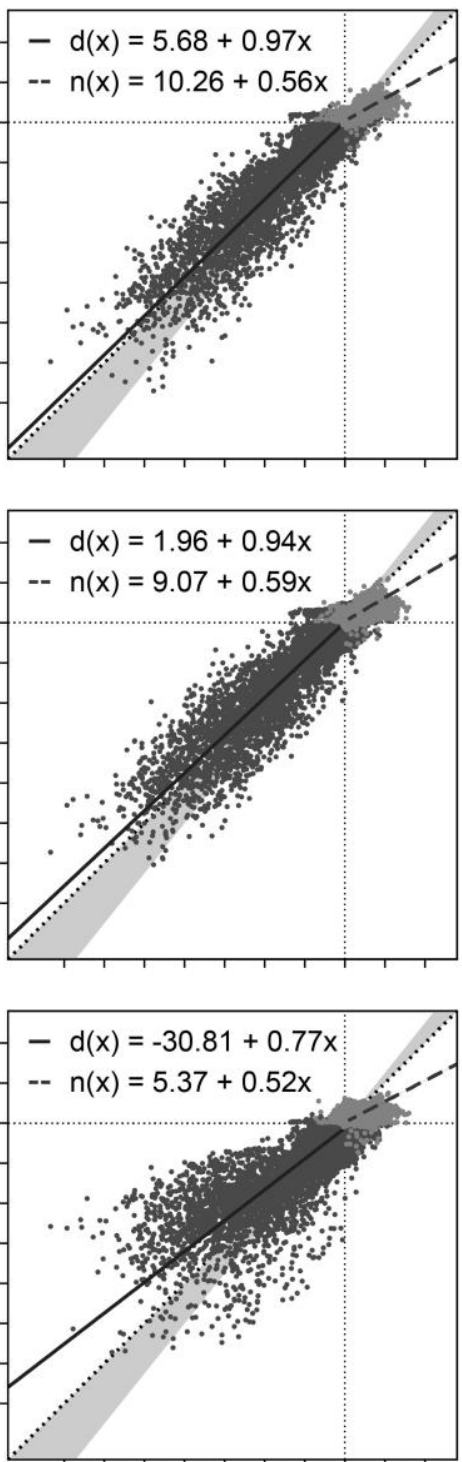

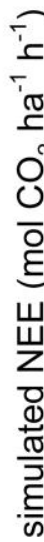

considering NEE $+\mathrm{R}_{\text {soil }}$

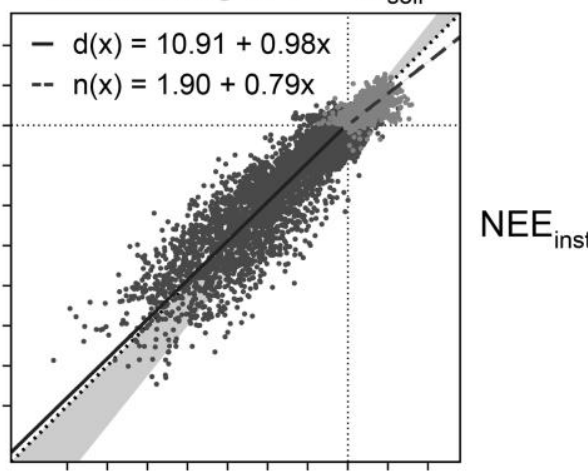

66
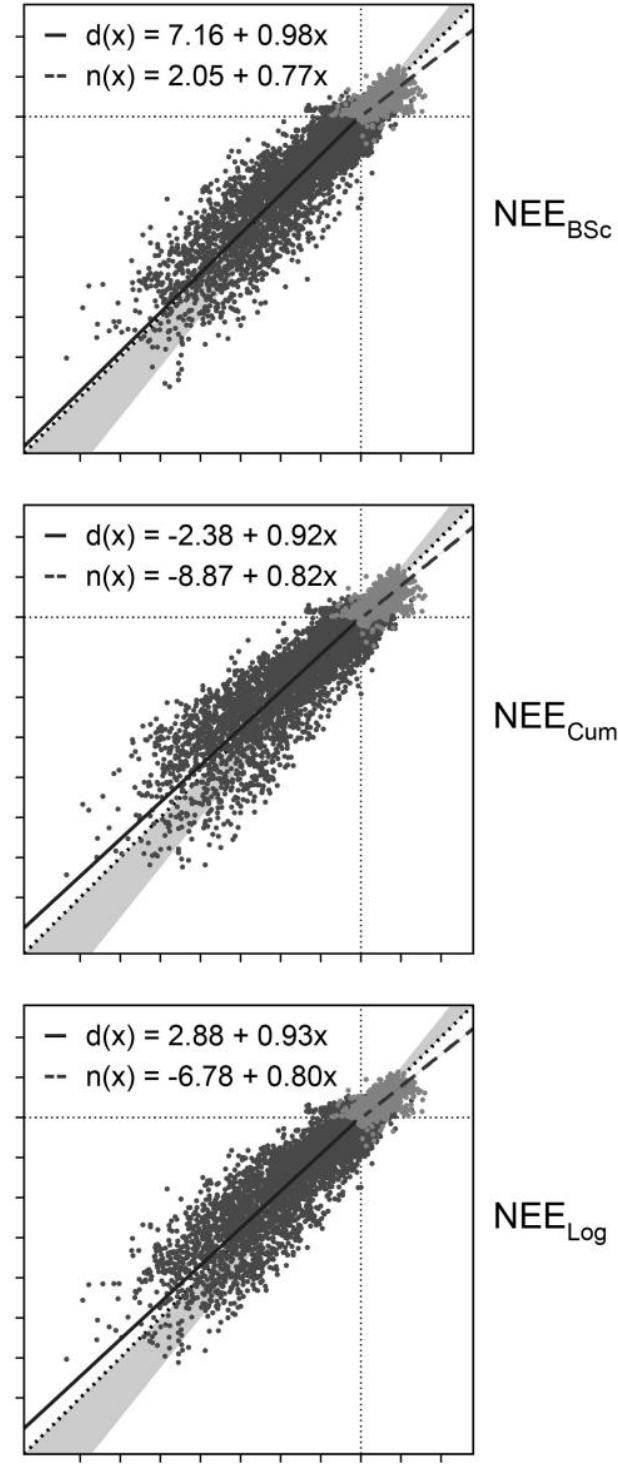

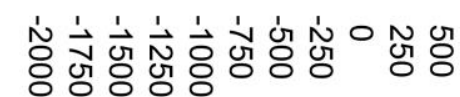

measured NEE $\left(\mathrm{mol} \mathrm{CO}_{2} \mathrm{ha}^{-1} \mathrm{~h}^{-1}\right)$

2 Fig. B.1:

3 Correlations between observed and simulated net ecosystem exchange (NEE) for all 4 optimization strategies at test site Merzenhausen. Reduced major axis regression was derived 5 for each strategy distinguished between day- (d) and nighttime (n) $\mathrm{CO}_{2}$ fluxes, whereat 6 nighttime was designated to a measured global radiation lower than $20 \mathrm{~W} \mathrm{~m}^{-2}$. For description 7 of optimization strategies see text. 

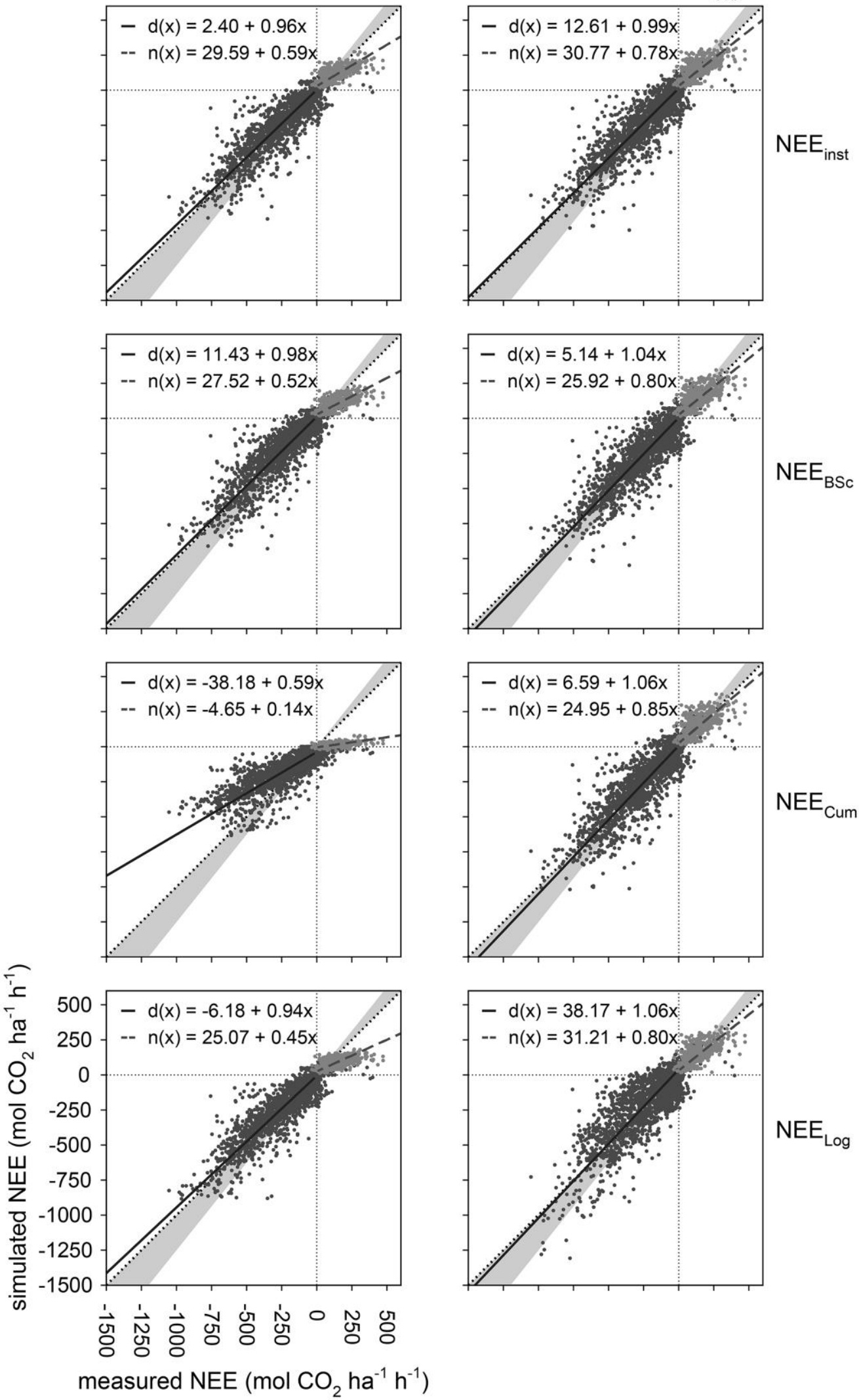

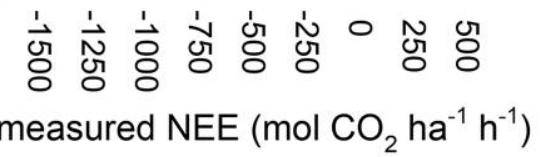

Fig. B.2:

2 Correlations between observed and simulated net ecosystem exchange (NEE) for all 3 optimization strategies at test site Rollesbroich. Reduced major axis regression was derived 4 for each strategy distinguished between day- (d) and nighttime (n) $\mathrm{CO}_{2}$ fluxes, whereat 5 nighttime was designated to a measured global radiation lower than $20 \mathrm{~W} \mathrm{~m}^{-2}$. For description 6 of optimization strategies see text. 

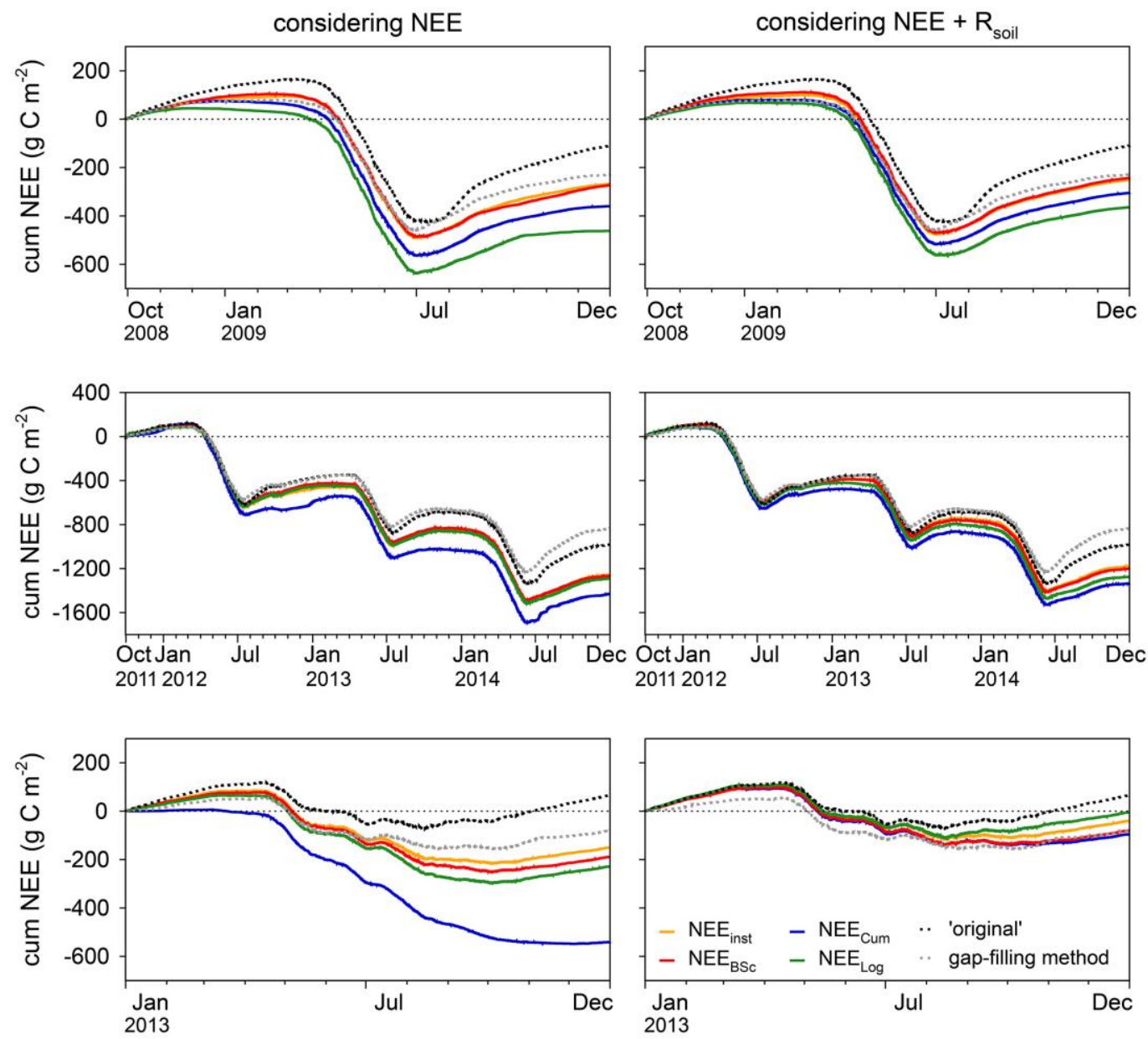

1 Fig. B.3:

2 Cumulated net ecosystem exchange (cum NEE) over simulation time period, calculated in 3 "gap-filling mode", for each optimization strategy, for the simulation without calibration to 4 NEE ('original'), and for the gap-filling method after Reichstein et al. (2005) (gap-filling 5 method) in Selhausen (top), Merzenhausen (middle), and Rollesbroich (bottom). For 6 description of optimization strategies see text. 